Portland State University

PDXScholar

Fall 12-15-2015

\title{
Isn't Citizen Science a Hoot? A Case-study Exploring the Effectiveness of Citizen Science as an Instrument to Teach the Nature of Science through a Local Nocturnal Owl-Monitoring Project
}

Tess Marie Kreofsky

Portland State University

Follow this and additional works at: https://pdxscholar.library.pdx.edu/open_access_etds

Part of the Science and Mathematics Education Commons Let us know how access to this document benefits you.

\section{Recommended Citation}

Kreofsky, Tess Marie, "Isn't Citizen Science a Hoot? A Case-study Exploring the Effectiveness of Citizen Science as an Instrument to Teach the Nature of Science through a Local Nocturnal Owl-Monitoring Project" (2015). Dissertations and Theses. Paper 2645.

https://doi.org/10.15760/etd.2641

This Thesis is brought to you for free and open access. It has been accepted for inclusion in Dissertations and Theses by an authorized administrator of PDXScholar. Please contact us if we can make this document more accessible: pdxscholar@pdx.edu. 


\title{
Isn’t Citizen Science a Hoot?
}

A Case-study Exploring the Effectiveness of Citizen Science As an Instrument to Teach the Nature of Science through a Local Nocturnal Owl-monitoring Project

\section{by}

Tess Marie Kreofsky

A thesis submitted in partial fulfillment of the

requirements for the degree of

\author{
Master of Science in Teaching \\ in \\ General Science \\ Thesis Committee: \\ William Becker, Chair \\ Stephanie Wagner \\ Matthew Collins
}

Portland State University

2015 


\begin{abstract}
Citizen science projects present a distinctive opportunity for professional and volunteer scientists to coordinate their efforts to gather unique sets of data that can benefit the scientific and local communities. These projects are assumed to be an effective educational tool to teach nature of science (NOS) to participants (Brossard, Lewenstein, Bonney, 2005). This case study evaluates the effectiveness of participation in a citizen science project as a way to learn about NOS. Through enhancement of the Tryon Creek Owl Monitoring Project the researcher reviewed the characteristics of a citizen science project that were thought to be necessary to impact the volunteers' knowledge of NOS. The study also explored the benefits and limitations to organizing the citizen science protect using the principles of action research. Analysis of participants' knowledge and the effectiveness of active research theory, was evaluated through preand post- questionnaires and interviews. Although volunteers were able to explore the core themes of NOS through actively engaging in the scientific process, they did not experience a statistically significant change in their demonstration of understanding. For a multitude of reasons, participants had a positive experience with the presence of an embedded researcher within the project. This case study supports the use of active research as a guide to ensure that within each project the needs of both the scientific community and the volunteer scientists are met.
\end{abstract}




\section{Acknowledgements}

Firstly, I would like to express my sincere gratitude to my advisors Stephanie Wagner, Cary Sneider, and Melissa Potter for their continuous support of my Master's

study and related research, for their patience, motivation, and immense knowledge. Their guidance helped me in all the time of research and writing of this thesis.

Besides my advisors, I would like to thank the rest of my thesis committee: William Becker, and Matthew Collins, not only for their insightful comments and encouragement, but also for their hard questions which incented me to challenge my research from various perspectives.

My sincere thanks also goes to Matthew Collins again and his colleagues and volunteers at Friends of Tryon Creek who provided me an opportunity to join their team as an educator, and who gave access to the nature center and park facilities. Without their precious support it would not be possible to conduct this research.

Also I thank my fellow classmates of the MST program. I am forever grateful for the many hours spent editing, learning and creating together.

Last but not the least, I would like to thank my family: my parents and to my sister for supporting me spiritually throughout writing this thesis and my life in general. 


\section{Table of Contents}

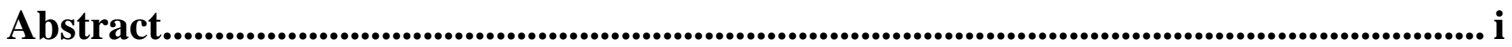

Acknowledgements ................................................................................................................ ii

List of Tables .................................................................................................................. iv

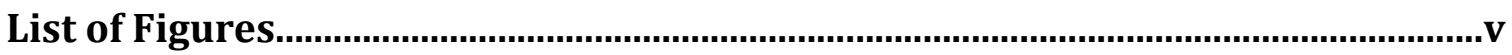

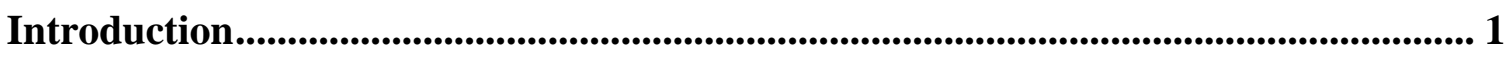

Review of Literature ........................................................................................................... 5

Purpose of Citizen Science .................................................................................... 5

Assessment of citizen science project and future impact ............................................. 9

Citizen Science Project Model .............................................................................. 16

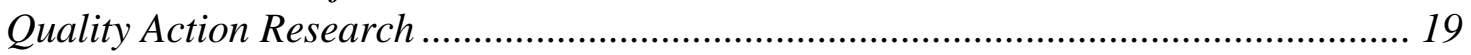

Assessing knowledge of Nature of Science …………................................................. 20

Methods............................................................................................................................................ 23

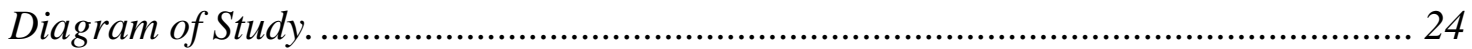

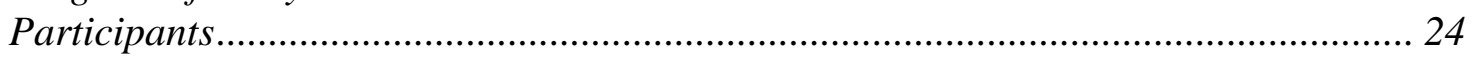

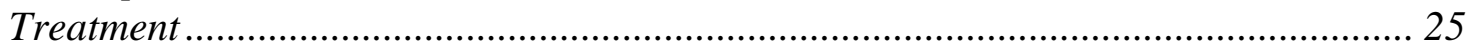

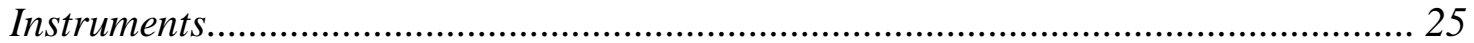

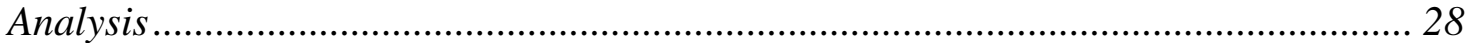

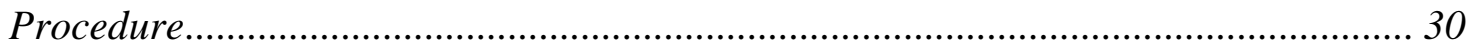

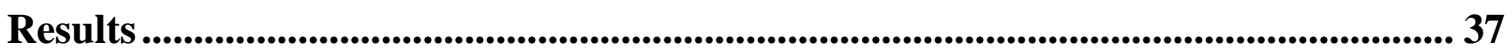

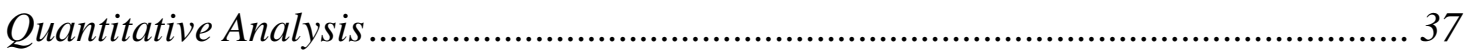

Qualitative Data.......................................................................................... 40

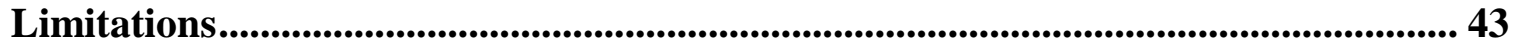

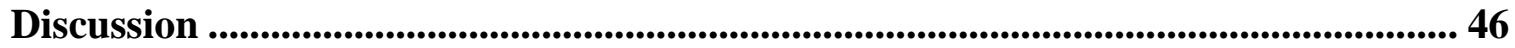

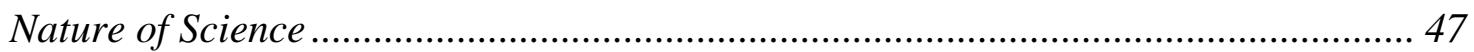

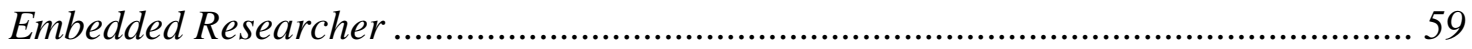

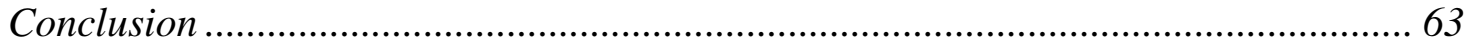

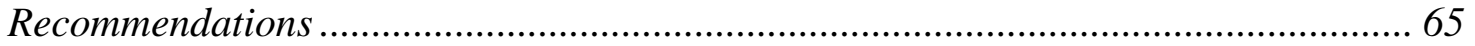

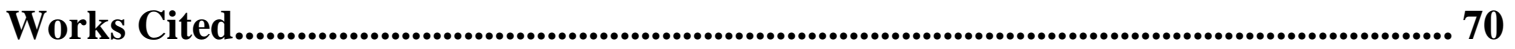

Appendix A: Survey and Interview Questions................................................................... 72

Appendix B: Coding Instruments ......................................................................................... 75

Appendix C. Tables and Charts ............................................................................................... 76 


\section{List of Tables}

Table 1: Experimental Design...............................................24

Table 2: Study Timeline.................................................. 31

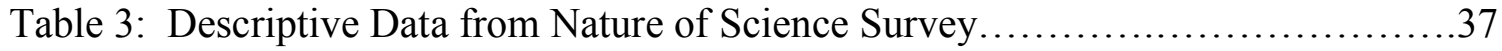

Table 4: Final Analysis of Nature of Science Survey.............................. 38

Table 5: Frequency data from Interview Responses about Embedded Researcher.......40

Table 6: Coding results from NOS questions on Interview, Version 2................42 


\section{List of Figures}

Figure 1: Bar Graph of Pre- and Post-Survey Results............................. 38

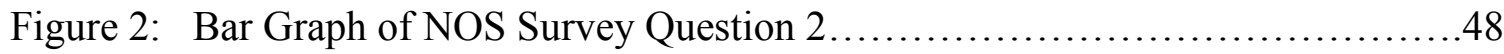

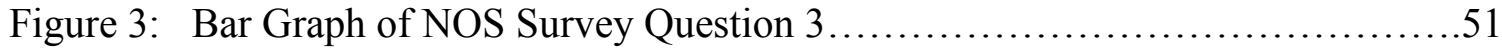

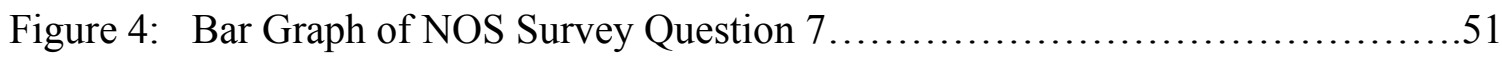

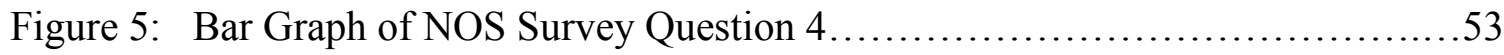

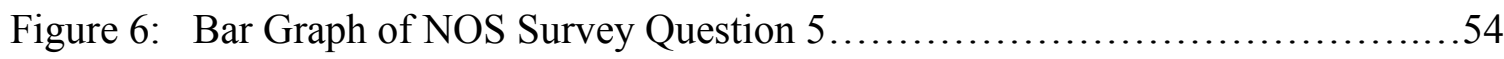

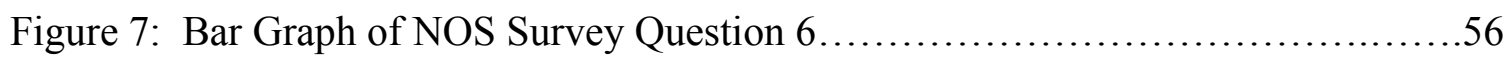

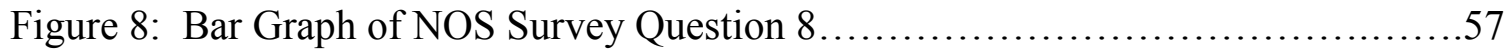




\section{Introduction}

Tryon Creek State Natural Area was established in 1971 through a collaboration of concerned local citizens and Oregon State Parks. The park is filled with native forests and lush riparian areas, which are a typical characteristic of the surrounding Willamette Valley. The park is deeply nestled in South West Portland and receives hundreds of daily visitors including hikers, bikers, joggers and naturalists.

In November 2011, Friends of Tryon Creek and volunteers began gathering baseline data on the nocturnal owl community that inhabits the park. The Tryon Creek Owl Monitoring Project was designed to monitor the five owl species that overwinter and breed within the park: Great Horned Owl (Bubo virginianus), Northern Saw-whet Owl (Aegolius acadicus), Northern Pygmy-Owl (Glaucidium californicum), Barred Owl (Strix varia), and Western Screech-Owl (Megascops kennicottii). Annually volunteers learn a new monitoring protocol and spend two nights per month for three months, sometimes in the rain or snow, listening or calling for the owls. Unfortunately, lack of funding and support from the scientific community has limited the amount of time the park staff could give to the project and its volunteers for the past three years. Currently there is no other citizen owl-monitoring occurring in the Portland area. Common national bird surveys rarely include nocturnal owl species; therefore the data being collected at Tryon Creek may hold valuable information for owl monitoring and conservation efforts throughout North America (Levesque 2002).

Historically avian monitoring projects are assumed to be the most successful type of citizen science project. Researchers teach their participants about bird biology as 
well as science literacy through teaching the participants to monitor birds at a desired location. The owl monitoring project is smaller than many existing bird focused citizen science research, such as eBird or the Backyard Bird Project hosted by the Cornell Lab of Ornithology. Although participants are gathering observational data in both scenarios, the literature holds little evidence that citizen science projects, large and small, effectively teach participants about the Nature of Science. The overarching purpose of the following case study was to support the efforts of the Tryon Creek Owl Monitoring Project.

To qualify this project as action research, the evolution of the owl project included a collaborative effort of both myself (the researcher), and the participants. Upon my reflection and assessment of this transition I reviewed and analyzed the effectiveness of organizing a citizen science project to imbed the researcher in a way that enabled volunteers to gain a holistic understanding of the nature of science while also providing valid scientific data.

The case study was completed through four steps:

1) investigating the history of the project, through the eyes of the previous volunteers;

2) redesigning and reenergizing the current Tryon Creek Owl Monitoring Project and

3) supporting the collection of data on owl distribution and breeding behavior within Tryon Creek State Natural Area.

4. testing for a change in participants' knowledge of NOS

The independent variable of the research was the monitoring project as it exists now and the dependent variable was the volunteers' definition of aspects of science that are consistent with the following aspects of Nature of Science (NOS) as summarized by National Research Council (NRC, 2012, Nature of Science pg. 4):

- Scientific Knowledge is Based on Empirical Evidence

- Scientific Knowledge is Open to Revision in Light of New Evidence 
- Science is a Way of Knowing

- Science is a Human Endeavor

These aspects of NOS were specifically written for application through the Next Generation Science Standards in a K-12 setting. However the NRC believes that the implications of these aspects do not change for the Nature of Science experienced at any age, place or time, further emphasized in the statement "...there is a strong consensus about characteristics of the scientific enterprise that should be understood by an educated citizen" (NRC, 2012, page 78). A deep understanding of NOS requires that students (participants) experience scientific practices in an authentic context (NRC, 2012.) During the study, the owl monitors of Tryon Creek had the opportunity to continuously apply four of the scientific practices while the group developed an investigation and improved the monitoring process together. The practices were written by the NRC based on an investigation of what scientists actually do and therefore were deemed "essential for all students to learn and describe," when learning about the Nature of Science (NRC, 2012, Ch. 3).

The scientific practices used during this project are listed below:

- Asking questions

- Planning and carrying out investigations

- Analyzing and interpreting data

- Constructing explanations

Nature of Science refers to a collection of values and assumptions that are necessary during the pursuit of scientific knowledge. Currently, the common framework for measuring science literacy depends on an individual's understanding of the basic concepts of NOS, and their knowledge of the utility of those concepts within the context of their everyday life (Schwartz, Lederman, Crawford 2004). This project assessed the 
owl monitors' understanding of the above NOS aspects and the utility of those aspects within the context of the owl-monitoring project and local owl conservation.

The second purpose of this study was to help the researcher identify benefits and limitations to conducting a citizen science project through the participation of an embedded lead researcher, a unique aspect that defines the project as action research, or a co-created project (Bonney et al, 2009b). To meet the criteria of action research, this research project was facilitated as a partnership between the researcher and practitioners (owl monitoring volunteers and staff) for the purpose of empowering and transforming the Tryon Creek Owl Monitoring Project (Bradbury Huang 2010). The embedded researcher worked alongside the monitoring volunteers and staff at Friends of Tryon Creek Nature Center through two reviews, revisions and one implementation of the Owl Monitoring Project in an effort to achieve the intended knowledge and science goals. 


\section{Review of Literature}

The body of literature describing the effects of participation of citizen science projects on volunteers' knowledge is comprised of three areas of research that I address below. First, I explore the potential of citizen science projects to contribute to professional scientific research, through a variety of case-based articles. Second, I describe how the educational effectiveness of citizen science for participants has been assessed in the past and discuss the impacts those evaluations are likely to have on the future of citizen science. Finally, I introduce the alternative route of studying citizen science, action research, and the Views of Nature of Science Questionnaire, one of the most contemporary ways of measuring Nature of Science (NOS).

\section{Purpose of Citizen Science}

Delaney, Sperling, Adams and Leung (2007) described a citizen science project designed to locate and monitor invasive species along the East Coast of the United States. The project monitored species like the Asian Shore crab, which reproduce at an alarming rate. This is one of many adaptable traits that allow the invasive species to take over native aquatic communities easily and quickly, which may be advantageous to these aliens, but to conservationists it is a nightmare. Early detection is the most cost-effective eradication method for this aquatic invasive and this technique requires continuous monitoring. Delaney et al. recruited 1,000 volunteers to continuously monitor 52 coastal sites over a four-month period. The information they collected was used to create a baseline database of distribution and abundance of the native and invasive crab species in 
the selected areas. This baseline data provided the information necessary for the authors to predict the rate and direction of distribution of the invasive species included in this study.

Delaney et al. found some unexpected patterns when they measured accuracy of their volunteers' data through a computer analysis. The authors suggested that accuracy of data gathered by each volunteer was correlated with their age and educational background through a co- linear relationship $(\mathrm{r}=0.813)$. Students in grades 3-7 collected data with a high accuracy rate of $80 \%$, while adults with some college education hit $90 \%$ accuracy. Through the hard work of these volunteer scientists of all ages, with the guidance from professionals, the United Sates now has a better understanding of the conservation efforts needed to protect the entire East Coast from invasive crab species.

Hurlbert and Liang (2012) used 10 years of data collected by citizen scientists for the project eBird, to measure the magnitude of shifts in migration phenology (the behavior of an animal) in relation to the changing climate. Over the past century, the average atmospheric temperature has risen $.74{ }^{\circ} \mathrm{C}$, with most of that increase happening over the past 10 years. Seasonal temperature shifts change the date of resource availability, such as food, for migratory animals such as birds. Many scientists have been tracking the shifts in migration phenology, but few have measured the magnitude of these changes. The authors compared the spatiotemporal variations in migration shifts of 18 bird species across the United States east of the Mississippi River and in two Canadian provinces. They also questioned whether these changes were related to the fluctuation in the average spring temperature. The authors found a mean arrival date (MAD) for each 
species. The MAD was used to compare the difference between migration phenology in short-distance migrators (within the United States) and long-distance migrators (into the United States). Analysis of this relationship revealed that MADs did shift an average of 0.8 days earlier as a response to the changing spring temperatures for all species. The strength in the shifts in migration phenology was different for each species, depending on their migration length and speed. Species with a short migration were able to more easily adapt their migration time to the local seasonal cues and arrive at a time of optimal resource abundance. Birds with longer migrations depended more on photoperiod (hours of daylight) as a cue to fly north. The consequence is that they were not able to adjust as well and had later arrival times. Long-distance migrators must migrate faster or face the challenge of finding enough resources (nest sites, food, etc.) to sustain their population. This collaboration of concerned citizens and science professionals will allow conservationists to better manage bird nesting habitat and to make more accurate predictions of how migrating species will be affected by future climate changes.

Worthington, Silvertown and Laurence, et al (2012) described methods used to train volunteers who participated in Evolution MegaLab. This citizen science project is one of the largest surveys of polymorphism performed in a field setting. This was also the first citizen science project used to study the effects of climate changes on the evolution of a species, which in this case was the banded snail. Without the help of volunteers a project of that magnitude would have been impossible to complete due to time and funding limitations. The methods used to train Evolution MegaLab participants were based on the need to facilitate volunteers' understanding of the project's purpose and to 
ensure they collected quality data. The requirements were to: (i) write a valid scientific question designed with volunteers in mind; (ii) recruit motivated volunteers; and (iii) verify the data through assessment of volunteers' understanding and scientific analysis. Over 6,000 volunteers from 15 countries surveyed 2 species of banded shell snails in hopes of tracking evolutionary changes in shell polymorphism. To satisfy requirement one the lab asked a simple scientific question that was applicable to the 15 different countries. Volunteers were then trained through a robust MegaLab homepage filled with pertinent information that is necessary for accurate data collection and the understanding of the project's intent. To meet requirement three researchers used an online quiz to assess the volunteer's knowledge of their task and biology of the snails. If volunteers answered wrong, the quiz would reinforce the learning process by providing feedback with biological information and pictures. Evolution MegaLab was used to facilitate a hands-on learning opportunity for its volunteer scientists, while also contributing data to the field of knowledge on the relationship between evolution and climate change.

In summary, authors of the previous three articles realized the intrinsic value of citizen science projects to scientific research and the need to understand the effects that climate change can have on organisms. Each project was designed to enable researchers to gather massive amounts of data through a collaboration of professional and volunteer scientists across a large geographical range in a timely and cost effective manner. Delaney, Sperling, Adams and Leung (2007) described how volunteer and professional scientists work together to track the distribution and movement of invasive species in relation to the changing climate. Hurlbert and Liang (2012) recruited participants to help 
scientists understand how climate changes affected the migration patterns and survival of 18 bird species. The project described by Worthington, Silvertown, and Laurence, et al (2012) was designed to balance sufficient training of volunteer scientists, while also tracking the changing morphology of banded snails over time across Europe. Although citizen science projects were being used to contribute mass amounts of data to conservationists' efforts to understand the effects of climate change on life on earth, its potential as an educational tool is only slowly being discovered.

\section{Assessment of citizen science project and future impact}

During the 1990's scientists designed citizen science projects with the assumption that their volunteers would emerge more science literate than before the participation began. Little research on this subject existed until 2000 when Trumbull, Bonney, Bascom and Carbal tested this assumption by reviewing the letters of over 700 participants from the citizen science project called the Seed Preference Test (SPT). This project was coordinated by the Cornell Lab of Ornithology (CLO) in 1994 and attracted 17,000 participants. Volunteers were collecting data to help researchers learn what types of seeds birds prefer while at ground feeders. Each participant was given a research kit that explained methods, protocol and provided literature on science and its processes. Over 600 volunteers completed post-project questionnaires that were designed by CLO and intended to assess participants' belief in and knowledge of science.

The authors were unable to draw any conclusions on their volunteers' gain of knowledge because of their volunteers' high median age of 49 , and the fact that $70 \%$ of 
them held a bachelor's degree. The authors believed that their participants started volunteering with an understanding of the process of science so it became impossible for the authors to tell how much knowledge was gained during the project. Next the authors assessed volunteers' understanding and beliefs in regards to the process of science through evaluating letters written by participants in the SPT. Three CLO staff rated the letters for evidence of learning about the process of science. This analysis was also inconclusive because categorization became too theoretical and complicated. The authors did learn that understanding of the project's intent and purpose was not as clear to volunteers as they had assumed. Overall the authors realized the importance of knowing their audience before designing and assessing a citizen science project.

Little is known about the effects citizen science participation can have on the knowledge and perspectives that volunteers have on science and conservation. Brossard, Lewenstein, Bonney (2005) created a standardized scale of measurement for assessing this effect. They tested these evaluation methods on a citizen science project called The Birdhouse Network (TBN), where volunteer scientists gather data on the nest preference of cavity dwelling birds. Through a series of pre- and post-tests, the authors assessed participants' learning about bird biology, the nature of science and whether volunteers experience a change in attitude toward science. The authors' methods are different from those used in similar research studies, because they compared the results against social norms and theoretically driven evaluation questions. The pre-test was sent to the first 300 participants to sign up, which safeguarded that they answered the questions before they read the education materials provided by TBN. The control group consisted of 400 
randomly selected Cornell Lab of Ornithology members that did not participate in TBN. The authors then sent a post-test to 200 randomly chosen participants who did not receive the pre-test and 200 that had completed the test.

The authors' defined attitude through the Elaboration Likelihood Model (ELM) of persuasion. ELM refers to a tool used to measure participants' interest in a subject, in order to estimate how easily they could be positively persuaded to believe it is true. To measure a gain in the understanding of the scientific process, the authors coded test responses according to the methods of the National Science Foundation's science and engineering indicators (NSF, 1996). The authors found no significant evidence supporting the assumption; TBN Participation changed volunteers' understanding of science. However, other results show that participation in TBN led to a knowledge gain of bird biology. The authors' evaluation of attitude change was inconclusive because of their struggles in defining attitude and the fact that their participants started out with a positive attitude toward science and environmentalism. This article outlined the struggles of assessing a citizen science project, while also recognizing a few of its uses and limitations when used as an educational tool.

Trumbull, Bonney and Grudens-Schuck (2005) set out to develop and test a curriculum folded within a citizen science project designed to help middle school students use inquiry thinking. The authors had an overarching goal of creating a framework for teaching inquiry. The material was titled Classroom FeederWatch (CFW) and was based on the National Science Education Standards, published in 1996. CFW was the first citizen science experiment written for a classroom setting. During the project 
students gathered information about bird abundance, distribution and which seed type the birds prefer. Over 200 teachers from 32 states tested this material. The authors used a pre- and post-test assessment to measure change in the students' knowledge of bird biology, attitude about conducting science and understanding the applications of ideas related to inquiry. To their dismay, the authors found little to no change in the students' knowledge of each category in question. Their evaluation of the material led to three recommended revisions. First, they realized the need for better integration of bird biology and the process of inquiry in the material in hopes of better preparing the teachers and students to complete successful experiments. Second, the authors added information on how to conduct ornithology-specific or discipline-specific experiments. Next, the authors wrote of the importance of approaching assessments with a broad definition of inquiry to better meet the National Science Education Standards. This article described the importance of assessment when trying to use citizen science projects as a learning tool for any audience of any age.

According to Crall, Jordan, Holfelder, Newman, Graham and Waller (2012) the popularity of citizen science programs increases yearly, though the body of literature on the effectiveness of these projects as an educational tool is dismal. Methods used to analyze the educational outcomes are not standardized; therefore projects cannot be compared. In their article, Crall et al. evaluated the effectiveness of a training regime used to prepare volunteers for a citizen science project that is designed to study invasive weeds. The authors chose this project due to the particular importance of successful education during projects involving invasive species. Because humans are often the 
vectors of these aliens, it is essential that participants leave the citizen science experience comprehending the implications of invasions and how they can be prevented.

Crall et al. hypothesized that the training modules increase volunteers' understanding of the scientific methods, global positioning systems (GPS), vegetation monitoring and invasive species ecology. The authors predicted that the knowledge gain would be different for participants depending on their level of experience with science. To test their hypothesis, Crall et al. used pre- and post-tests to assess whether a knowledge gain was present and whether their volunteers experienced a change in attitude and literacy, and then compared that to the volunteers' levels of prior experience.

During the treatment, participants completed four training modules, each $30-45$ minutes, which were designed to educate them on invasive species ecology, GPS use, and a standardized protocol for data collection. The volunteers were asked questions about their environmentally conscious behavior, their perception of the science inquiry process, and their science literacy in the subject of the study. Three evaluators categorized the volunteers' answers into 5 categories.

Crall et al. found no significant gain in the participants' understanding of the scientific process even when a volunteer had extensive prior experience in similar projects. The authors also found no change in participants' attitude toward science and the environment, which Crall et al. attributed to the positive attitude reported by their volunteers' prior completion of the training. Participants reported a change in behavior during the project and they projected they would continue these behaviors after the projects completion, but follow-up research was not conducted. Overall, the authors 
continued to press the importance of using or creating standardized methods of analysis so that other evaluators could compare projects across a broad range of subjects. They also gave weight to designing projects that motivate participants' learning through ensuring the project answers questions on a local scale, when also collecting data across a large geographic range.

Without capturing the interest and motivation of the general public, citizen science projects would not exist. GalaxyZoo is a citizen science project that is considered to have one of the highest rates of participation with over 200,000 volunteers from over 113 countries. Raddick, Bracey, Gay, Lintott, Murray, Schawinski, Szalay, and Vandenberg (2010) created techniques used to determine the motivation and demographics of GalaxyZoo volunteers. Raddick, et al. evaluated 237 participants' responses to the question, "What makes GalaxyZoo interesting?" They also investigated participants' motivation by completing 30 -minute interviews with 22 volunteers. Through their analysis, they defined 12 categories of motivation for participation in Galaxy Zoo: contribute, learning, discover, community, teaching, beauty, fun, vastness, helping, zoo, astronomy, and science. The most common motivator was an interest in astronomy, rated at $46 \%$ frequency for all responses. The authors wrote of the importance of crosschecking written and oral assessments, to provide sufficient certainty that categories of motivation can be accurately identified. They concluded that knowing your target audiences' motivation for participation will increase recruitment levels and may also lead to a more successful citizen science project.

Jordan, Ballard and Philips (2012), described citizen science as a partnership 
between professionals and non-scientists for the purpose of collecting valid data to be shared and analyzed. The authors tackled defining and evaluating key issues for the assessment of learning outcomes of citizen science participants in hopes of enhancing the effectiveness of future projects.

According to Jordan, Ballard and Philips, the assessment process begins prior to a project's start date. First, researchers should define the learning goals for their project, then write learning outcomes. Outcomes should be detailed, measurable, obtainable and realistic to the specific project. Next, researchers should design an evaluation with the purpose of confirming that learning goals are aligned with activities and learning outcomes are clear. Evaluation plans must include understandable and realistic indicators for learning success, so that they can be measured during the assessment process. The authors suggested exploring outcomes more broadly than direct participation, because their research suggested that citizen science projects can also have an impact at the community level. They encourage project leaders to consider the impacts on how a community shares resources, well-being of the community and if there is a change in social capital.

The preceding articles described a progression of methods for evaluation of citizen science projects as an educational tool. Each article framed a new method, built to test the hypothesis that volunteers will gain knowledge, and/or change their behavior or attitudes towards science and the environment through participation of a citizen science experiment. Tumbull et al. (2000) employed theoretical analysis to assess a change in volunteers' science literacy through the evaluation of letters written by participants. 
Brossard et al. (2005) started the movement towards the use of pre and post-test assessment, while also creating the first standardized method of comparing volunteers' knowledge to social norms. Tumbull et al. (2005) discussed the limitations and misconceptions behind designing citizen science projects that take place in a classroom setting. Crall et al. (2012) tested the educational effectiveness of a training regime designed to have sufficiently trained and educated volunteers while still ensuring the project met participants' needs. Raddick et al. (2010) explored the motivations of their projects' participants in hopes of providing an educational setting that is tailored to their volunteers' interests. After a number of studies found little evidence that citizen science projects were the successful educational tools program developers had assumed, researchers began to build a general framework for designing projects with assessment techniques woven throughout. Jordan et al. (2012) summarized the theories and methods of successful analysis of effectiveness while still motivating and satisfying educational and professional needs of the participants and scientists. These articles support the need for a standardized method of analysis in order for projects to be compared across subject fields. They also discuss the need to understand participant's motivation, learning intentions and background before a successful training can be implemented.

\section{Citizen Science Project Model}

The Cornell Lab of Ornithology (CLO) is one of the leading hosts and researchers of citizen projects. Bonney, Cooper, Dickinson, Kelling, Phillips, Rosenber and Shirk (2009), staff of the CLO, published a model for developing a citizen science project based on carefully selected principles, themes and theories that the CLO defined after 
years of studying these projects. The model includes 9 steps that research confirmed are the most crucial characteristics of an effective and successful citizen science project.

According to the model, the first step in a citizen science project is to choose a scientific question. Often times this research relies on the capabilities of amateur observers, therefore it is important to choose a question that relies on basic skills. Complicated projects tend to attract fewer participants and require more time and resources from project managers.

Secondly, the model emphasized the importance of establishing a crossdisciplinary team of support, specifically: scientists, educators, technologists and evaluators. Support personnel with scientific backgrounds often help enhance scientific integrity, accuracy, and ensure quality data. Education experts have the ability to develop and communicate training material that is clear and easy to use by amateur scientists. Evaluation experts are helpful in ensuring the project has measurable objectives and evaluations to check that objectives are met.

Data quality is a challenging aspect for a citizen science project. The third step is to only use protocols, data forms and educational support material that have been tested and refined. According to research, a volunteer scientist's ability to collect and submit accurate data depends on the clarity of the data collection form, that which must be simple and logical in nature. There also needs to be support and training available to volunteers about how to follow protocols and submit data.

The fourth step is to recruit participants with simple materials developed specifically for the target audience. The amount and complexity of recruitment will 
depend on the breadth and complexity of the proposed citizen science project.

Participants must be trained before they participate in a citizen science project. In most citizen science projects at the CLO, training is offered online. Participants or group leaders are responsible for ensuring that the training is completed.

Step six of the model is to ensure results are made known to the volunteers who worked hard to collect the data. Accepting, editing and displaying the data can lead to three times higher rate of participation when compared to projects that did not process and share their results. Step seven is to analyze and interpret the data during the process in coordination with step six. Citizen science projects are designed to help collect data that is often impossible for professional scientists due to breadth, time, resources and other complications. Professional analysis and interpretation of citizen science projects at the CLO have revealed previously unknown trends in migratory bird behavior due to the changing climate.

Results of citizen science projects are often unique datasets that should be shared with the field of science in order to enhance the body of literature. Step eight is to disseminate the results to the appropriate scientific community. The final step in a successful citizen science project is to measure outcomes, to ensure that both the scientific and educational objectives were accomplished. These results too should be shared with educational and scientific communities to ensure a continual enhancement of the body of literature on the accomplishments and characteristics of successful citizen science projects. 


\section{Quality Action Research}

Action research projects seek legitimate understanding of a current situation (economic, social, education, etc.) through experiential learning alongside local participants. "Action research" (AR) is a broad term used to describe a social scientist becoming a partner with a targeted group of people (practitioners) to generate knowledge toward a collective benefit. AR is unique from other social research because of its intimate nature of the relationship between researchers and practitioners.

In 2010, Action Research professional, Bradbury Huang, wrote an article on what constituted quality AR, how it was used in the past and why it has gained popularity as a research technique. According to Huang's framework for AR, step one of a quality project would be to facilitate a way for the researcher (scientist) and practitioners to discuss and shape research questions and designs together. The author emphasizes the partnership should not just be coordinated solely with the leader of a community or the CEO of a company, but instead with a variety of practitioners involved in the same situation representing a variety of perspectives. Step two is putting the co-designed project into action. Step three occurs after the initial trial of the collectively designed action plan when the researchers and practitioners make adjustments to the research or action plan based on reflection of how effective the plan has been. Because of the continued reflexive reporting (self-reflection), claims and misconceptions are conceptualized and addressed as they occur, and the complexity of the situation being studied becomes transparent. In a quality AR project the trial-and-error cycle would continue until resolution is met or the researcher reaches a design giving sustained 
empowerment to the targeted group of practitioners.

Huang writes about three aims that must be met in order to deem AR as "good". First the Practical aim is met through ensuring the practitioners goals and concerns are met and beneficial to their cause. The second aim is Technical and would be met by ensuring the researchers performed quality work. The Emancipatory aim ensures that the AR is based on the goal of making the practitioners' situation better and stronger.

In her article, Huang summarizes three recent AR projects to display its broad application in social science.

1. AR was used to help identify how to give marginalized women of Japan the opportunity to have a voice in urban planning of their small villages. Scientists and practitioners worked closely to create a kit that outlined the steps necessary to evaluate, address and work to solve urban planning issues to ensure the sustainability of the empowerment established by the isolated female population.

2. AR was used to help an engineering firm to identify and eradicate time management weaknesses within the office.

3. A graduate student used AR to create a partnership between local engineers, social scientists, and organization leaders to identify why organizations are not using low carbon technologies. The project resulted in the formation of new alliances between 6 local organizations and a sustainable effort to address future impediments.

\section{Assessing knowledge of Nature of Science}

For the past 85 years educators have debated how to teach Nature of Science (NOS). That conundrum remains unanswered today, but researchers like Lederman, 
Abd-El-Khalick and Schwarts (2002) felt that a new Views of Nature of Science (VNOS) questionnaire and interview-combination helped teachers evaluate the teaching method they employed in their own classroom. Historically, educators assessed NOS understanding with yes or no questionnaires only. VNOS questionnaires are unique in that they asked open-ended questions that allowed the learner to explain and give examples that supported their answers. VNOS questions evaluate the learners understanding of six core aspects of NOS: scientific knowledge is tentative; empirical; theory-laden; partly the product of human inference, imagination, and creativity; and socially and culturally embedded. The authors administered one of three versions of VNOS to over 2000 high school, college and graduate students and graduates, as well as, pre-service and in-service elementary and secondary school teachers. The VNOS was coupled with 500 interviews that validated the understanding of the learners' answers.

The authors believe yes/no-questionnaires of the past were biased by the writer, who analyzed answers with the assumption that the respondent understood the statements in the same way they did. Along with bias, past tests did not enable the assessor to explore the nature of the learners' NOS understanding; therefore they were unaware of common misconceptions and other weaknesses in their lessons that hindered their students' learning. Through use of validating follow-up interviews biases that were characteristic of prior instruments were eliminated in the VNOS.

Due to the broad definition of NOS used to analyze the questionnaires, the VNOS allowed educators to assess the understanding of a wide variety of individuals. When the answers were analyzed, each one may address only one or multiple aspects of VNOS. 
The creators of the VNOS intended that the questionnaire be administered with few limits on time, answers and writing space to ensure no impingement on the respondents' answers.

The literature describes the importance of teaching science inquiry within the scientific context of the projects. The premise of citizen science is that by experiencing these practices within the context of hands-on data collection, the audience will have an easier time understanding where scientific information comes from and how it can be used (Trumbull et al. 2005, Crall et al. 2012, and Jordan et al. 2012). However, the research literature to date indicates that this is not usually the case. Therefore, the researcher in this case study provided support through a unique approach to citizen science. This approach was organized after the tested model proposed by the leading lab of citizen science research, CLO (Bonney et al. 2009a). The hypothesis of the study was that the progressive nature of action research methods would allow deeper understanding of the learner's view of NOS, providing enough insight for the researcher to enhance the learners' understanding of the subject.

This proposed action research project inspired collaboration between graduate students, Friends of Tryon Creek, citizen scientists and Portland State University in an effort to preserve Portland's nocturnal owl population. By conducting the projects as action research, the researcher teamed up with practitioners to locate the impediments to teaching NOS aspects through gathering reliable scientific data to promote owl conservation. 


\section{Methods}

This case study assessed the effectiveness of teaching the core themes of NOS through participation in a local citizen science project. To do so, professionals and volunteer scientists coordinated their efforts to empower the Tryon Creek Owl Monitoring project in a way that allowed for sustainable generation of knowledge and authentic scientific data collection in the future. By approaching this renovation as an action research project, the volunteers explored aspects of NOS and the scientific practices throughout the editing and implementation process. The researcher evaluated the progress of this partnership's efforts to review, revise and rework the monitoring project through four steps:

1. investigating the history of the project, though the eyes of the previous volunteers

2. redesigning and reenergizing the current Tryon Creek Owl Monitoring Project

3. supporting the collection of data on owl distribution and breeding behavior within Tryon Creek State Natural Area

4. assessing for change in participants' demonstration of understanding of NOS

Participants' understanding of four core themes of NOS were tracked and measured through their response to a pre- and post-treatment survey. Volunteers elaborated on their understanding through a post-treatment interview. This interview was used to probe participants' understanding of NOS if they were uncomfortable with the online survey format.

To assess the benefits and limitations of embedding the leading researcher within a citizen science project, the researcher conducted pre and post interviews with new and seasoned volunteers. Interviews also provided the participants with the opportunity to 
direct the redesigning of the monitoring project.

\section{Diagram of Study.}

Table 1. Experimental Design with multiple waves of measurement.

\begin{tabular}{|l|l|l|l|l|l|}
\hline N1 & $\mathrm{O}_{1}$ & $\mathrm{I}_{1}$ & $\mathrm{X}_{\mathrm{R}}$ & $\mathrm{O}_{2}$ & \\
\hline $\mathrm{N} 2$ & $\mathrm{O}_{1}$ & $\mathrm{I}_{1}$ & $\mathrm{X}_{\mathrm{R}}$ & & \\
\hline $\mathrm{N} 3$ & & & $\mathrm{X}_{\mathrm{R}}$ & $\mathrm{O}_{2}$ & \\
\hline $\mathrm{N} 4$ & $\mathrm{O}_{1}$ & & $\mathrm{X}_{\mathrm{R}}$ & & $\mathrm{I}_{2}$ \\
\hline
\end{tabular}

$\mathrm{N}=$ non-random grouping of participants

N1 = Participants that took both the pre-and post-surveys

N2 = Participants that took only the pre-survey

N3 = Participants that took only the post-survey

N4 = Participants that took the pre-survey and post-interview

$\mathrm{O}_{1}=$ Survey Parts A

$\mathrm{I}_{1}=$ Interview Part A

$\mathrm{X}_{\mathrm{R}}=$ Revised Training and Protocol

$\mathrm{O}_{2}=$ Survey Part B

$\mathrm{I}_{2}=$ Interview Part C

\section{Participants}

Tryon Creek State Nature Area attracts people of all ages from the surrounding metropolitan area. Over 70\% of Owl Monitoring Project participants were Caucasian, over 30 years of age, and familiar with the park because they were either residents in the surrounding neighborhood or nature enthusiasts who visit the park regularly. Volunteers were generally motivated to participate due to their interest in owls, bird biology, conservation, or community involvement. Their current NOS understanding was unknown to the researcher when the case study began. 
This study included 31 volunteers, recruited from various sources. The project was advertised in community newsletters and the Friends of Tryon Creek newsletter, posted on Portland State University campus and emailed to education and biology departments of Lewis and Clark College and Portland State University. The online pretreatment questionnaire was offered to all participants and interviews were conducted with the 12 volunteers that offered their time.

\section{Treatment}

The treatment was the owl monitoring project the participants helped to create. Volunteers were submersed into a more extensive training curriculum than in the past years of the project. This consisted of training on a new protocol, which they evaluated at the end of the training. Training also provided opportunities for participants to explore four NOS concepts and scientific practices through learning material, and analysis and application of the data. The entire process allowed for more participant involvement in the research design than was available in the past. Further details of the treatment are described in Procedures.

\section{Instruments}

This study utilized three instruments: an online NOS survey and two interviews.

NOS Survey. (Appendix A). The NOS survey was based on the Next Generation Science Standards (NGSS) learning progressions written for $12^{\text {th }}$ Grade to test participants' understanding of the four selected aspects of NOS (NRC, 2012). 
- Scientific Knowledge is Based on Empirical Evidence

- Scientific Knowledge is Open to Revision in Light of New Evidence

- Science is a Way of Knowing

- Science is a Human Endeavor

Survey questions were written based on the expected level of NOS understanding of a high school senior as outlined by the National Research Council in Appendix $\mathrm{H}$ of the Next Generation Science Standards (Appendix A). The survey questions were written by Stephanie Wagner, a Professor of Science Education at Portland State University and Matthew Collins, the Education Director of Friends of Tryon Creek.

The survey format asked participants to give their opinion on statements representative of each NOS aspect by the use of a Likert scale. Through asking participants to explain the reasoning behind their answer, the researcher hoped to gain an accurate interpretation of their demonstration of understanding for each aspect. To ensure participants understood the format of the scale, correctness was formatted in a descending and ascending order.

The pre-treatment questionnaire was sent to all current participants in November 2014 via SurveyMonkey.com. All participants were invited to complete the same survey during March 2015.

Interview 1. (Appendix A) During this case study, participants were presented with an opportunity to remodel the Tryon Creek Owl Monitoring Project and share their experiences with previous iterations of the project. Volunteers shared their opinion of the renovation through a 30-minute, in-person interview. This interview consisted of ten questions, each designed to draw out the educational, scientific and personal needs and 
desires of the participants.

Questions one through three were designed to let the respondent express what they liked and disliked about the project in the past, along with an option to describe what they wanted out of the modified project. The next five questions were written with the intension of understanding the structure and interworking of the past project and how each respondent perceived it. The final two questions were designed to provide the researcher with insight on the scientific content offered and volunteers' knowledge gains through previous participation in the project.

Interview 2. (Appendix A) Interviews are a common tool used in education research to gain deep insight into a learner's understand of a specific topic (Fry, Ketteridge, \& Marshall, 2008). Due to a lack of voluntary participation in the post-survey, an interview was implemented to ensure that the researcher understood participants' understanding of the nature of science. Each question of the post-treatment survey was designed to inspire an explanation of the participants understanding of a specific NOS aspect within the context of the owl monitoring project. The questions were modeled after the VNOS, open-ended and pertaining to science in a real-life scenario (Lederman, Abd-El-Khalick and Schwarts, 2002).

The first two questions examined the volunteers' motivations and confirmed those motivations were addressed through participation in the project. Question three was intended to expose understanding of the theme; Scientific Knowledge is Based on Empirical Evidence, through asking respondents if the data they collected could be used 
to further scientific knowledge. Through asking participants to describe the possible outcomes of data fluctuation over time question four revealed volunteers' understanding of the NOS aspect, Scientific Knowledge is Open to Revision in Light of New Evidence. Question five was aimed at the core idea; Science is a Way of Knowing, by asking participants to brainstorm ways that society can influence the use and collection of scientific data. Question six addressed understanding of the theme, Science is a Human Endeavor. Through this question participants explained their interpretations of what determines a scientist's ability to be truly objective.

The eighth question examined participants' experience with and opinion of the presence of an embedded researcher within the monitoring project. Questions nine and ten offered an opportunity for participants to express feedback and revision of the project format. The interview concluded with a request to share the participants' favorite aspects of the project. This simple question was written with the intention of helping future project managers understand the critical aspects required to keep participants satisfied and returning.

To ensure face validity of each question, the researcher collaborated with two Portland State University faculty members from the Center for Science Education to design interview questions.

\section{Analysis}

NOS Coding Sheet. (Appendix B) Each completed questionnaire was coded and eventually compared to measure for changes in volunteers' ability to demonstrate an 
understanding of NOS. The NOS coding sheet is structured as a rubric consisting of a list of the 4 core themes of the nature of scientific knowledge, accompanied by a list of corresponding learning outcomes that should be understood by a high school student according to the NGSS (NGSS, 2013). One question was added to the post-survey, with the intention of capturing a clear understanding of the participants' experience with and opinion of the presence of an embedded researcher within the project. Face validity of the survey and the corresponding coding rubric were tested through the consultation and collaboration of Stephanie Wagner and Matthew Collins.

NOS Coding Statistical Analysis. The uneven number of survey participants between the pre- and post-survey led to a small sample size of only six participants that took both the pre- and the post-survey. A sample size that small meant that the researcher had to assume the underlying population is normally distributed, which led to the use of two ttests. A Welch's t-test was employed identify significant change in survey answers between the pre- and the post-survey. The researcher ran the test on both the total participants of each test (pre-test $n=23$ and post-test $n=8$ ) and the smaller group of participants that opted to take both tests $(\mathrm{n}=6)$. This test was chosen because it allowed for the assumption that the means of each population were the same, but that their variance was different.

Next, a Wilcoxon t-test was used to detect any significant change between the population that took both the pre and the post-test. This test was used because it does not hold the same normality assumption as the Welch's, therefore; it provided a more 
accurate $\mathrm{p}$-value.

Coding Sheet for Interview. The researcher created this scoring guide by reading through the initial interviews and dissecting out common themes from each participant's answers. The frequency of each theme was noted and correctness of that theme was defined by the NOS aspects and understandings provided on the NOS coding sheet (Appendix B).

\section{Procedure}

The following case-study was completed in multiple phases, each designed to facilitate the collaboration of Tryon Creek's volunteers and staff to help the researcher build a new owl monitoring project while also evaluating its effectiveness as an education tool to develop participants' understanding of core nature of science themes.

Phase 1. Friends of Tryon Creek advertised for volunteer owl monitors through email to their general volunteer list and returning volunteers, biology and education departments at two local universities and through multiple community weekly newsletters.

Two weeks before the project training event all who signed up for the training or had participated in the project in the past were invited to participate in a pre-treatment survey hosted by the website SurveyMonkey (see Appendix A). During that same time period an email was sent to the 12 returning monitors inviting them to participate in an in-person interview \#1 (see Appendix A). Out of the returning monitors, five volunteered to participate in the pre-treatment interview process. 
Table 2. Timeline of the study of the Tryon Creek Owl Monitoring Project in 2014-2015

\begin{tabular}{|c|c|c|c|c|c|c|}
\hline & November & December & January & February & March & April \\
\hline $\begin{array}{l}\text { Phase 1: } \\
\text { Open online } \\
\text { NOS pre-survey }\end{array}$ & X & & & & & \\
\hline $\begin{array}{l}\text { Interview } \\
\text { returning } \\
\text { volunteers }\end{array}$ & $X$ & & & & & \\
\hline $\begin{array}{l}\text { Revision of } \\
\text { protocol and } \\
\text { methods }\end{array}$ & $X$ & & & & & \\
\hline $\begin{array}{l}\text { Phase } 2: \\
\text { Code interviews }\end{array}$ & $X$ & & & & & \\
\hline $\begin{array}{l}\text { NOS survey } \\
\text { coded }\end{array}$ & $\mathrm{X}$ & & & & & \\
\hline $\begin{array}{l}\text { Phase 3: } \\
\text { Training event }\end{array}$ & $X$ & & & & & \\
\hline $\begin{array}{l}\text { Phase 4: } \\
\text { Second revision } \\
\text { of protocol and } \\
\text { methods }\end{array}$ & & X & & & & \\
\hline $\begin{array}{l}\text { Phase 5: } \\
\text { Owl monitoring }\end{array}$ & & $\mathrm{X}$ & $X$ & $X$ & $\mathrm{X}$ & $X$ \\
\hline $\begin{array}{l}\text { Discussion of } \\
\text { local } \\
\text { conservation } \\
\text { issues } \\
\end{array}$ & & & $X$ & & & \\
\hline $\begin{array}{l}\text { Phase 6: } \\
\text { Online NOS } \\
\text { post-survey }\end{array}$ & & & & & & X \\
\hline Post Interviews & & & & & & $\mathrm{X}$ \\
\hline $\begin{array}{l}\text { Final revision of } \\
\text { protocol and } \\
\text { methods }\end{array}$ & & & & & & $X$ \\
\hline
\end{tabular}

Phase 2. Each interview was coded to interpret the volunteer's ideas on how to change the project and to get a general consensus on aspects of the project that worked or did not work.

Coding of the survey was done by use of a rubric based on the NGSS standards for NOS understanding. The researcher consulted Portland State University staff about analysis techniques and results to ensure face-validity. Each answer on the Likert-scale 
gave a level of correctness with one of the polar ends being completely correct. If the participant's answer on the scale was incorrect, they were given a chance to provide a correct answer within an explanation. If the participant was unable to answer either the explanation or the scale correctly, their answer was considered incorrect. The researcher used NOS learning progressions or understandings defined by NGSS. Each explanation provided on the survey was compared to the learning progressions that are required for each NOS aspect according to NSGG (Appendix B). If the participant's explanation matched at least one of the understandings their answer was considered to be correct.

For example: When given the choice to rank their opinion on the statement, "Science is a human endeavor," a participant chose Neutral, but their explanation is, "Scientists' backgrounds, theoretical commitments, and fields of endeavor influence the nature of their findings." Although one of their answer types was incorrect, they are correct according to NGSS (Appendix B).

Phase 3. Next, the researcher began the process of rewriting the current owl-monitoring project based on the volunteers' interview answers. This aspect of the revision also involved the creation of a more rigorous training curriculum, as well as providing more opportunities for the volunteers to practice the Scientific Practices listed above, such as, analysis and interpreting data they collected.

The new training curriculum began with a 4-hour orientation event located at the Tryon Creek State Natural Area Nature Center, one month before the owl-breeding season began. The training day ran between 9-1pm, with lunch included. During the 
training the researcher provided copies of the new protocol and datasheet. The main intervention was given through a lecture that included material on the following subjects:

- History of the Tryon Creek Owl Monitoring Project, including a data summary, past and present scientific purpose and questions.

- History of owls throughout human culture.

- Background on owl research including: complications of studying a nocturnal species, how data can be used, importance of top predators, and owls as environmental indicators.

- Owl research at Tryon Creek, including: purpose and protocol

- General bird identification

- Ecology and biology of the five owl species living in the park

During a lecture intermission the participants were broken into groups and given one hour to practice working with the research tools (compass and stopwatch), while also practicing the new protocol and filling in the datasheet. The researcher and a park staff were available to assist with each activity. Monitors then reconvened to have a discussion reflecting on their experiences with the new protocol and methods. This discussion provided the volunteers with an opportunity to practice asking questions about and planning the investigation they would carry out in the following months. During this time the researcher was noting volunteer suggested revisions that would be put into place before the official season began.

Phase 4. One week after completion of the training event, the researcher completed the second revision of the project according to staff and volunteer comments provided at the training. Two weeks before the actual monitoring season began volunteers received the new protocol, methods, and datasheet, along with online resources on identifying owls by call within a package delivered by email. 
Phase 5. Once the owl breeding season began in early December, park staff and monitoring volunteers employed the new protocol bi-weekly until the end of March. Prior to each monitoring session, the researcher provided a 15-minute presentation on owl ecology, conservation research or owl call identification at the Nature Center. The participants chose the topic of each mini-lecture. One week before each monitoring event the researcher would email participants with a request for a topic.

Beginning the second week of monitoring, when sufficient data was collected, the researcher hosted discussion of the data after each monitoring event. The researcher facilitated this dialogue, but participants provided the content and controlled the length. Discussions provided an opportunity for the participants to analyze and interpret the data, while also constructing simple explanations about owl behavior according to the volunteers' observations.

One week after each event the researcher sent out an email summarizing the data analysis from the previous week. The participants were also invited to reply with questions and suggestions pertaining to data analysis and collection.

During the first week of January, the researcher presented volunteers with three articles on a local owl conservation issue: the management of the invasive Barred Owl (Strix varia), a species breeding within Tryon Creek and observed by the monitors. The discussion material included two local newspaper articles and responses from the public in the form of letters to the editor. The following week a 30-minute discussion on the topic was hosted after the monitoring event. The researcher began the discussion with a 
brief history of the subject, and then opened the class for volunteer-led discussion of the subject.

Another discussion was held during the last week in January. This discussion was hosted online and the subject involved follow-up stories about the previous barred owl conservation issues and a new issue of the barred owl attacking local residents within a park.

As the breeding season progressed, the researcher began emailing resources on juvenile owl-call identification and behavioral information. The content matched the breeding timeline of each species. For example the Great Horned Owl (Bubo virginianus), was the first to be observed and the first to hatch, therefore information on great horned owl juveniles was sent out first.

Two weeks before the final monitoring session, the researcher prepared a lecture that summarized the data, research and discussions of the owl monitoring season. The researcher focused the lecture structure on the NOS aspects that volunteers demonstrated to understand the least according to analysis of the pre-survey. The last monitoring session began an hour early to make time for a complimentary dinner and the project summary.

Phase 6. Two week before the season was scheduled to end, the volunteers received an invitation to participate in the post-treatment questionnaire. They were allotted three days to respond. Only 8 participants opted to complete the post-online survey, therefore; an interview version of the survey was created to support small survey dataset (Appendix 
A). Within one week of the last monitoring event 9 individuals volunteered to take part in the 30-minute in-person interview that was also recorded and documented. The postinterview was intended to help the researcher grasp a more detailed view of the volunteers understanding of NOS, while also providing those volunteers an opportunity to reflect on their experience within the project and to suggest improvements.

After compiling the volunteers' evaluation and suggestions about the monitoring project, the researcher once again reevaluated and altered the Tryon Creek Owl Monitoring Project. Finally, Tryon Creek staff was given the final product that can be implemented and reworked for future owl monitoring. 


\section{Results}

\section{Quantitative Analysis}

NOS Survey. The following quantitative analyses were calculated from data collected from the online pre- and post-treatment survey. The eight-question survey was designed to measure the volunteer owl monitors' understanding of four aspects of NOS. Analysis was used to understand the participants' knowledge of NOS before the treatment began. . Upon review of the responses, it became apparent that participants did not understand question one, therefore; it was dropped from the study and is not included in the dataset or results presented below.

Table 3: Welch's t-test results for participants that completed the pre- and post-survey and those who took only a pre- or post-survey. Group A consists of participants that took both the pre- and the post-survey. Group B is composed of participants that took only the pre- or the post-survey. (Group A: n=6, Group B: Pre-survey n=23, Post-survey n=8).

\begin{tabular}{|c|c|c|c|c|c|c|c|c|}
\hline & \multicolumn{2}{|c|}{ Group A } & & & \multicolumn{2}{|c|}{ Group B } & \multirow[b]{2}{*}{$\begin{array}{c}\mathrm{t} \text { Test } \\
\text { Statistic }\end{array}$} & \multirow[b]{2}{*}{ p-Value } \\
\hline & $\begin{array}{l}\text { Pre- } \\
\text { survey }\end{array}$ & $\begin{array}{l}\text { Post- } \\
\text { survey }\end{array}$ & $\begin{array}{c}\mathrm{t} \text { Test } \\
\text { Statistic }\end{array}$ & p-Value & $\begin{array}{l}\text { Pre- } \\
\text { survey }\end{array}$ & $\begin{array}{l}\text { Post- } \\
\text { survey }\end{array}$ & & \\
\hline Mean & 0.732 & 0.75 & 0.17712 & 0.8631 & 0.806 & 0.861 & -0.49386 & 0.6321 \\
\hline $\begin{array}{l}95 \% \\
\text { Confiden } \\
\text { ce } \\
\text { Interval }\end{array}$ & -0.247 & 0.211 & & & -0.306 & 0.195 & & \\
\hline
\end{tabular}

Significant at $\mathrm{p}<.01$

A total of 23 people participated in the pre-survey, but only 8 participants responded to the post-survey $(n=8)$. This group of total respondents was labeled Group A during analysis. Group B was comprised of the six participants that took both the preand the post- survey. A Welch's t-test was used to detect statistically significant changes between participants' demonstration of understanding of NOS on the pre- and the postsurvey for the two groups. The test results showed no statistically significant difference 
was experienced in either group (Table 3).

Table 4. Results of Wilcoxon rank test that compare the pre- and post-scores of Group B. $n=6$

\begin{tabular}{|l|c|}
\hline Standard Deviation & 1.0328 \\
\hline $\mathrm{t}$ Test Statistic & -0.7906 \\
\hline $\mathrm{p}$-Value & 0.465 \\
\hline
\end{tabular}

Next, A Wilcoxon test was used to confirm that no statistical change in understanding of NOS was experienced in the group that took both the tests (Table 4).

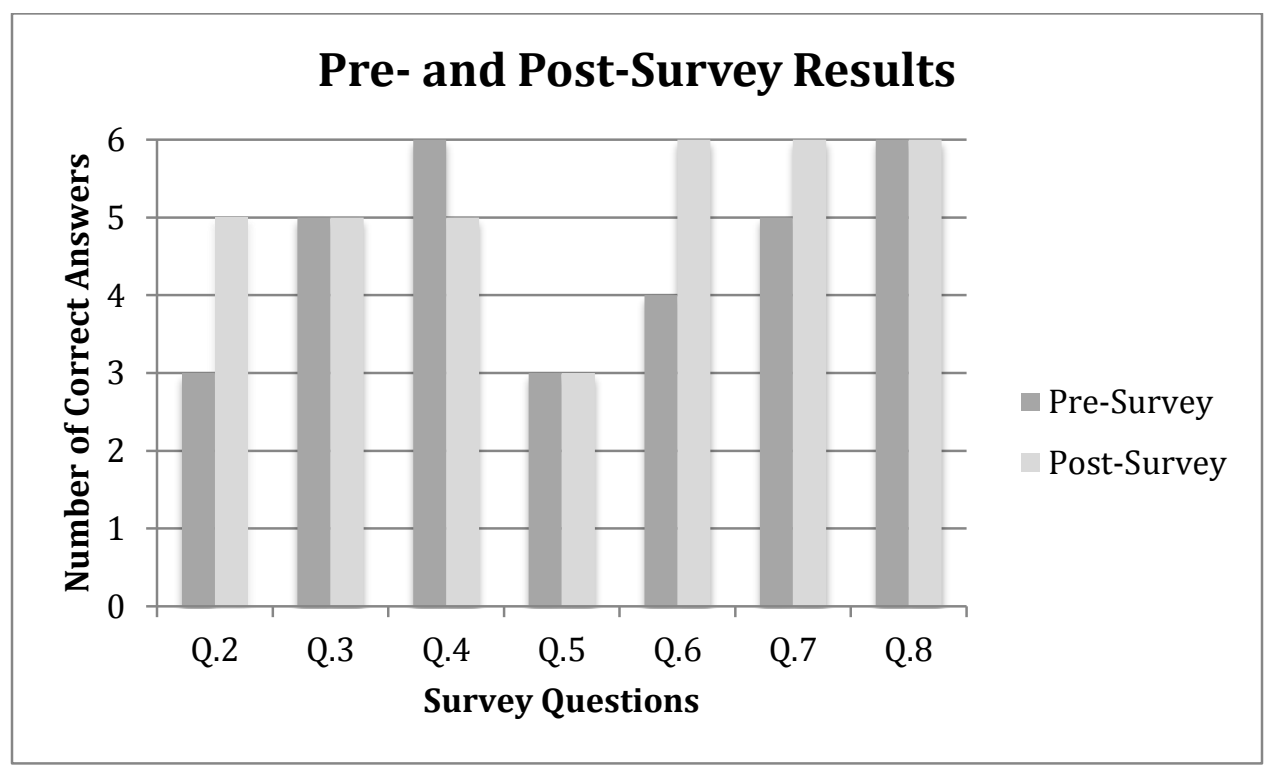

Figure 1. Comparison of correct answers per question (Q) answered on the pre- and post-survey. $(n=6)$

When comparing the number of correct answers given for each question on the survey, three out of the seven questions display a slight increase from the pre-survey to the post-survey (Fig. 1). That number was greatest for question two and six; the percentage of correct answers to the second question increased from $50 \%$ to $83 \%$ between the pre- and post-survey. Question two asked participants to give their opinion on whether science uses empirical evidence to describe natural phenomena. Question 
six prompted respondents to reflect on their level of agreement that science is a human endeavor. The percentage of correct answers for the sixth question increased from $67 \%$ on the pre-survey to $100 \%$ on the post-survey. Meanwhile, the number of correct answers decreased for questions four, when participants were asked to rate their opinion of the statement that science develops understanding of natural phenomena in a way that is different from religion or philosophy.

A group of participants that had completed the online survey also participated in a NOS interview with the researcher. Participants' answers were coded into themed explanations (Appendix C). Each question elicited multiple answers from the total group of participants. 


\section{Qualitative Data}

Embedded Researcher. A question about how the embedded researcher changed the participants' experience was asked during the post-survey (question 9) and post-interview (question 8) (Appendix A). One participant skipped this question on the survey.

Overall, most participants gave a positive review of their experience with an embedded researcher. Encouraging comments were provided from seven of the nine participants interviewed. Two participants stated that the embedded researcher did not change their experience.

Table 5. Frequency data from question 8 of the post-interview and question 9 on the post-survey. $n=11$

\begin{tabular}{|c|l|l|}
\hline Answer Category & Answer Themes & Total \\
\hline \multirow{5}{*}{ Positive } & - Provided stable structure & 2 \\
& - Added value and context & 2 \\
& - Reassuring that they were doing the right thing & 4 \\
& - Provided authenticity legitimacy & 2 \\
& - More organization and structure than before & 1 \\
& - Enhanced productivity and focus & 2 \\
& - More information and resources provided & 2 \\
& - More opportunity to discuss data and results & 1 \\
\hline \multirow{5}{*}{ Neutral } & - Already had scientific research experience, not & 1 \\
& there to learn about science & \\
& - Not at training and educational events & \\
\hline
\end{tabular}

Summary of results. The hypothesis driving this case study was that participation in a citizen science project with an embedded researcher would lead to an increase in the volunteers' ability to demonstrate understanding of NOS. According to analysis of data 
from the survey, no increase in accurate demonstration of knowledge was statistically significant. However, participants showed a slight increase in their understanding of the use of empirical evidence within a scientific framework when answering survey question two, and a minor increase in their understanding of scientific knowledge being a product of human effort when answering question 6. Participants' ability to demonstrate an accurate perception of the innate differences between scientific knowledge and religious or philosophical knowledge decreased for question 4.

Coding results of post-survey and post-interview responses pertaining to the experience with an embedded researcher, show that participants more frequently had a positive experience for a variety of reasons that will be expanded upon within the following section of this essay (Table 5). 
Table 6. Coding results of NOS question on during interview, $\mathrm{n}=9$

\begin{tabular}{|c|c|c|}
\hline Interview Question & Answer Themes & Total \\
\hline $\begin{array}{l}\text { Do you think the data we } \\
\text { collected could be used to } \\
\text { further scientific } \\
\text { knowledge? Why? }\end{array}$ & $\begin{array}{l}\text { - Yes - providing new data* } \\
\text { - Maybe - not sure of what classifies a project as real } \\
\text { science }\end{array}$ & $\begin{array}{l}4 \\
4\end{array}$ \\
\hline $\begin{array}{l}\text { If we ran this program } \\
\text { again next year do you } \\
\text { think we will get the } \\
\text { same data? If no, what } \\
\text { would that mean for } \\
\text { scientific knowledge? }\end{array}$ & $\begin{array}{l}\text { - No, natural changes in nature* } \\
\text { - No, natural changes in owl ecology* } \\
\text { - Maybe, if use same protocol } \\
\text { - Maybe, depends on knowledge and skills of } \\
\text { volunteers }\end{array}$ & $\begin{array}{l}4 \\
3 \\
3 \\
2\end{array}$ \\
\hline $\begin{array}{l}\text { How do you think society } \\
\text { can influence the use and } \\
\text { collection of a scientist's } \\
\text { data? }\end{array}$ & $\begin{array}{l}\text { - Through level of involvement (e.g. citizen science, } \\
\text { hunting)* } \\
\text { - Financial backing* } \\
\text { - Misinterpretation* }\end{array}$ & $\begin{array}{l}9 \\
2 \\
2\end{array}$ \\
\hline $\begin{array}{l}\text { Can scientist be } \\
\text { completely objective } \\
\text { within their research? } \\
\text { Please explain. }\end{array}$ & $\begin{array}{l}\text { - No, too many variables* } \\
\text { - Maybe, depends on the individual } \\
\text { - Yes, If try to avoid assumptions and be } \\
\text { conservative }\end{array}$ & $\begin{array}{l}3 \\
1 \\
1\end{array}$ \\
\hline $\begin{array}{l}\text { If we were given enough } \\
\text { resources and time could } \\
\text { we answer all scientific } \\
\text { questions about owls? }\end{array}$ & $\begin{array}{l}\text { - No, unknown and uncontrollable changes in nature* } \\
\text { - No, it just lead to more questions* } \\
\text { - No, too many assumptions* } \\
\text { - Maybe } \\
\text { - Yes }\end{array}$ & $\begin{array}{l}3 \\
3 \\
1 \\
2 \\
1\end{array}$ \\
\hline
\end{tabular}

*Demonstrates a knowledge of NOS 


\section{Limitations}

Budget. This citizen science project was hosted by the non-profit organization, Friends of Tryon Creek State Park. The organization has limited resources for staffing and materials for this project. Most of their resources were spent on volunteer recruitment. Financial constraints led to most educational material being available online only. This meant that participants were given limited time with the written material, which may have had an effect on how much they were able to learn during the treatment.

Time. Night surveillance added an aspect of complication to the study. Participants were asked to arrive early for each monitoring event in order to attend the mini-lecture. This timeframe was directly after most participants' workday and during the heaviest time of traffic. Participants often verbalized that they struggled to get to the monitoring session early and often only 3-4 people were able to attend the education lectures offered before the monitoring sessions. Participation in the learning activities may have also suffered due to the need to start at sunset, which is when commuter traffic is at its peak. The limited time that volunteers could commit restricted the time available to host discussions and extra lectures outside of the initial training event and may have had an effect on volunteers' gained in NOS understanding.

The limited time of park staff restricted the length of the monitoring season, so the time available for interviews, surveys and educational opportunities was shorter than planned.

Survey. Ideally evaluation tools should be tested and edited before put to use, but due 
time limitations within this case study the researcher was unable to field test the surveys before the project began (Bonney et al. 2009).

The researcher's use of voluntary recruitment for surveys and interviews led to the occurrence of censored data. Censoring is a condition in which the value of a measurement is only partially analyzed. (Vermeylen, 2005). The type of censoring that occurred within this study is referred to as left censoring. When participants in Group A completed only the pre-test, the researcher was unable to determine the surveyors' understanding of the 4 aspects of NOS after the treatment. Similarly, in the instance that participants took only the post-survey, the researcher was not able to determine the surveyors' comprehension of the NOS aspects before the treatment.

Small sample size. Participants were reluctant to answer the survey for the second time. Two participants reported that they felt like, "test subjects," because of the abstract nature of the questions on the survey. It may be that other people had similar feelings about the survey, but whatever the motivation may have been only six of the original 23 people took both the pre- and post- test. A sample of only six, meant the researcher was not able to test for normality of the distribution of the data. Due to this restriction the small group could not be used as a representation of the larger groups of people that took the pre and post-test. Testing for statistical significance became less accurate by having to assume that the underlying population was normally distributed.

Measurement of knowledge gain. Trumbell et al. (2000) reported their difficulty of measuring a gain of knowledge in a group that is already moderately informed in the 
subject of question. A similar situation occurred during the study of participants of the Tryon Creek Owl Monitoring Project. Pre survey results show that most participants could answer each question correctly about $80 \%$ of the time (Figure 2). When participants begin with an understanding they may experience a gain too small to measure with most assessment techniques. To correct for this in future studies the researcher may need to conduct a deeper analysis of their target audience before providing a pre-test and designing their curriculum (Trumbell et al., 2000). 


\section{Discussion}

Scientists and educators agree that science is a unique and valuable way of understanding the world. Since the late 1950's there has been a growing concern about the level of science literacy among the general public. With an increase in economic, social and environmental challenges the need for global citizens to make informed decisions about policy and management of resources is becoming crucial. However, being well informed about the use of science in daily life is not the same as understanding science and constant themes that act as scaffolding to true scientific knowledge. Science is a combination of practices, accompanied by a collection of knowledge that has been accumulated throughout history. A scientifically literate citizen is one that understands this framework (NRC, 2012).

Since the 1990s, citizen science projects have been used as a forum for science learning (Bonney et. al, 2009b). By facilitating an opportunity for scientists and the general public to work together towards a common scientific goal, many educators believe that this format is an effective way to import some knowledge of the procedures and approaches of science to those who are not scientists within an authentic context (Trumbell et al 2000, Bonney et al. 2009a, Raddick et al 2010, NGSS, 2013). The main purpose of this case study was to explore the usefulness of a small-scale citizen science project as a platform to teach participants about four major themes of scientific knowledge.

Research in science education has proven that students will gain a deeper understanding of scientific knowledge when giving the opportunity to explore science in 
an authentic and hands-on situation (Bonney et al. 2009a). Citizen science projects are often structured in a way that allows for participants to contribute first hand in the collection of scientific data that supports a scientific subject they find interesting. Commonly, these projects are designed for convenience, allowing the lead scientist or researcher to stay separate from participants, often only interacting through online trainings and emails (Bonney et al. 2009a). The researcher in this case study employed a different tactic modeled after action research, by embedding herself within the scientific process as it unfolds throughout the owl monitoring season. Through applying scientific practices alongside volunteer owl monitors to design, edit, enhance and apply the updated Tryon Creek Owl Monitoring, the researcher hypothesized that participants would increase their demonstration of understanding of the four aspects of NOS.

\section{Nature of Science}

Aspect 1. When applying critical reflection to problem solving or to new information that is claimed to be supported by scientific knowledge, citizens must first understand how to recognize the legitimacy of evidence used to back scientific claims. The first aspect of NOS explored in this case study is:

\section{Aspect 1: Scientific knowledge is based on empirical evidence.}

To enhance volunteers' comprehension of this aspect, the researcher of this study, set-up opportunities to allow participants to discuss past and present data collected throughout the project's history. The historical data was presented at a training lecture, followed by a continual open dialogue between participants and the researcher on how to best update 
the protocol and methods to obtain the data gathered during the monitoring period.

According to the design model for successful citizen science projects, allowing participants to manipulate and explore data is one of the most effective learning tools (Bonney et al. 2009). During this case study, the researcher provided this opportunity to expose participants to empirical evidence. Volunteer monitors would gather after each monitoring event to discuss the data they had just collected. Participants often used this time to look for possible patterns within the data and to ask clarifying questions about owl identification. After that data was submitted, the researcher analyzed and summarized it within the context of the evolving breeding season. The researcher would describe how the behavior and presence was changing as the season progressed.

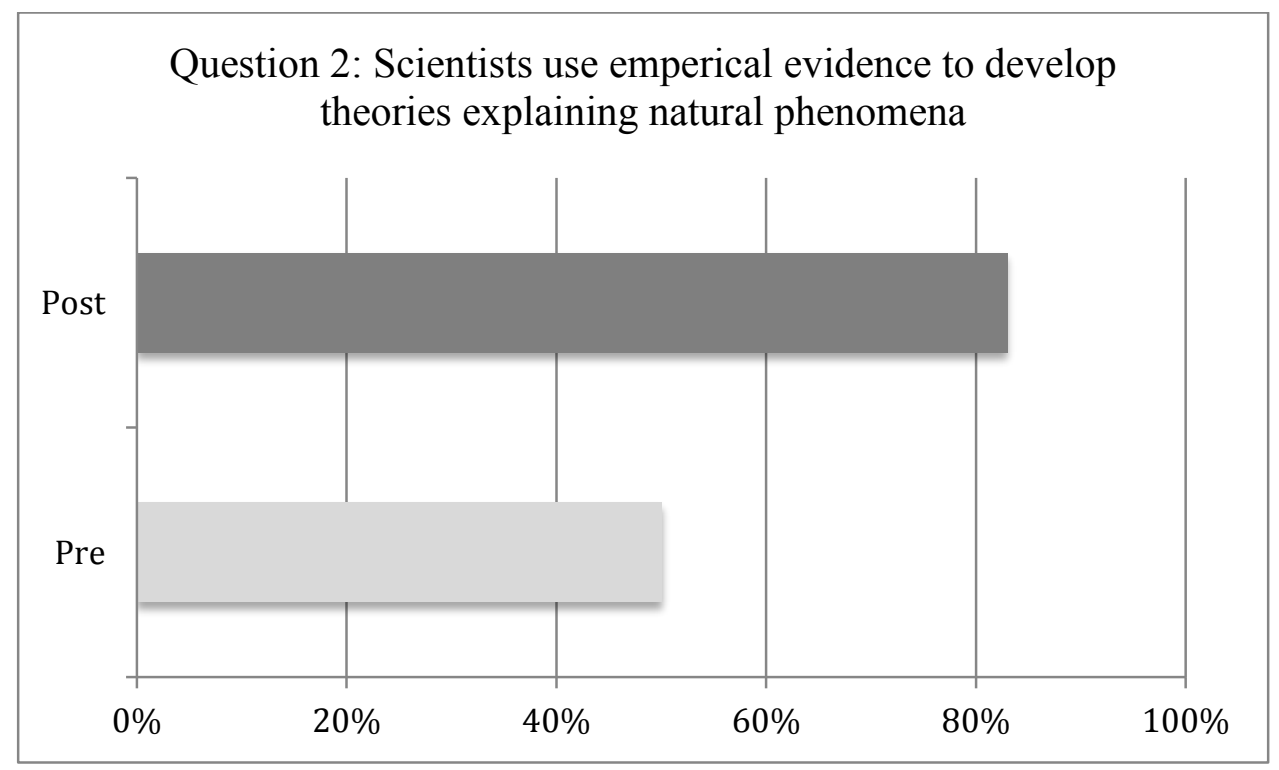

Figure 2. Average scores on the second question of the pre- and post-survey. $n=6$

Only half of the participants were able to demonstrate an accurate understanding of this core theme on the NOS survey prior to participating in the project, but that average 
increased after volunteers completed the monitoring project (Fig. 2). Although that change was not statistically significant, participants demonstrated an increase in their understanding of the type of evidence needed to support a scientific claim (Table 3). The participants were given opportunities to reflect on this NOS aspect throughout the treatment. For example, during one classroom discussion volunteers talked about the empirical evidence needed to justify lethal management of the barred owl in parts of North America. They identified that wildlife managers were not able to collect data on the historical aspect of the issue; therefore the policy was not supported by sufficient empirical evidence. During discussion of data collected at each monitoring event, participants were also able to describe the limitations of their observations as empirical evidence for claims on the behavior of the owls observed.

During the post-interview, volunteers were asked to expand on this understanding though deciding if the data they collected within the project could be used to inform scientific knowledge (Table 6). The most common themes from that question address the participants' uncertainty about what defines data that can be used to support scientific knowledge. The themed reasons for this uncertainty were:

- Lacking large enough quantity of data compared to other research projects - Lack of confidence with the data gathering process Themes from respondents that believed their data could be used in this way were:

- The data is new to the field of science, so it is important to science - They were witnessing change through collecting data over time In conclusion, participants were able to better demonstrate their understanding of 
the requirement for scientific knowledge when given the opportunity to express themselves in a group discussion. Time allotted for group dialogue allowed for participants to talk through questions about the data and questions based on their prior knowledge of the project and owl science. If structured appropriately, discussions may act as a formative assessment, and a guide to enhancement of training modules and background material.

Aspect 2. The second aspect of NOS in question pertains to the evolutionary nature of scientific knowledge.

Aspect 2: Scientific knowledge is open to revision in light of new evidence.

When trying to navigate decisions about continually changing scientific phenomena, such as climate change, nonscientists must first understand how professionals document and measure that change. To explore this NOS aspect through the owl monitoring project volunteers were provided with resources to learn about an invasive species and how their evolution can take them from a non-harmful resident within an environment to a source of environmental degradation. The invasive species used as an example was the barred owl, a common species at Tryon Creek State Park. Participants were asked to read about and discuss multiple opinions on this topic, as well as reflect on their own values that drove their opinions on the barred owl as an invasive species. 


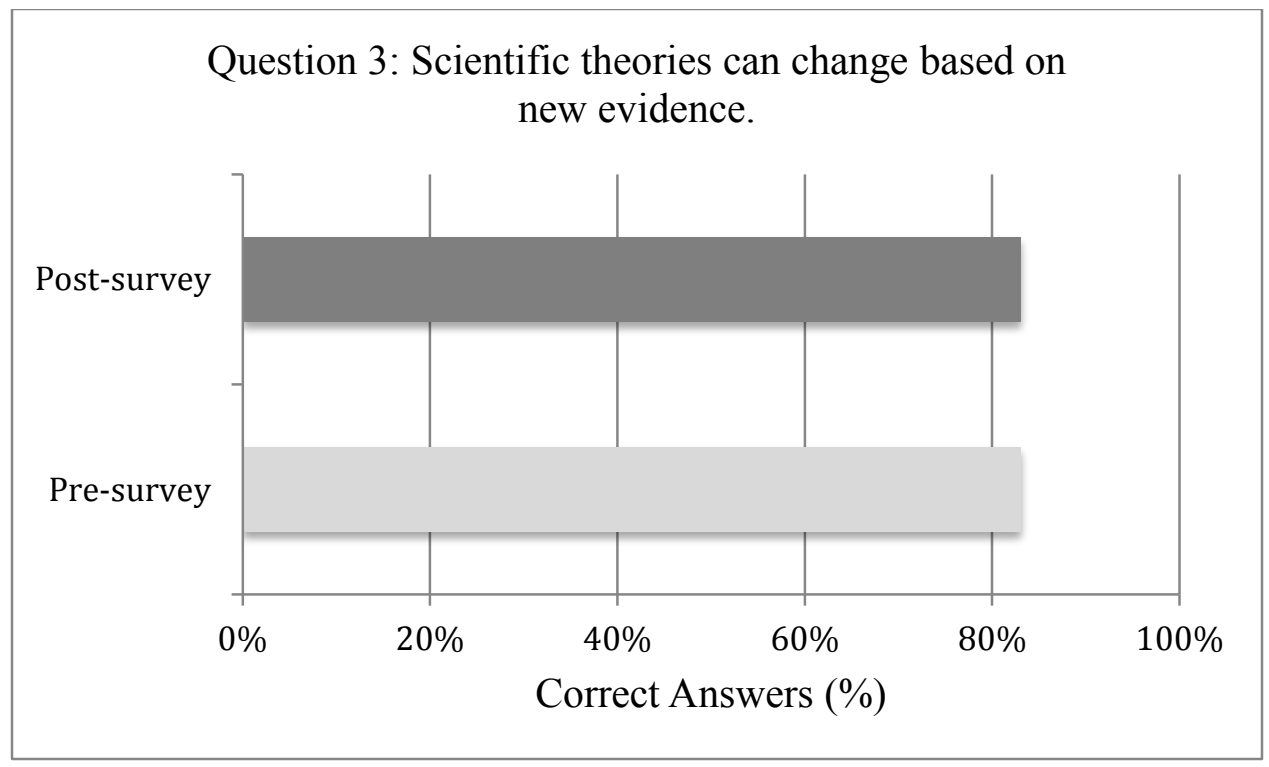

Figure 3. Average scores on the third question of the pre- and post-survey. $n=6$

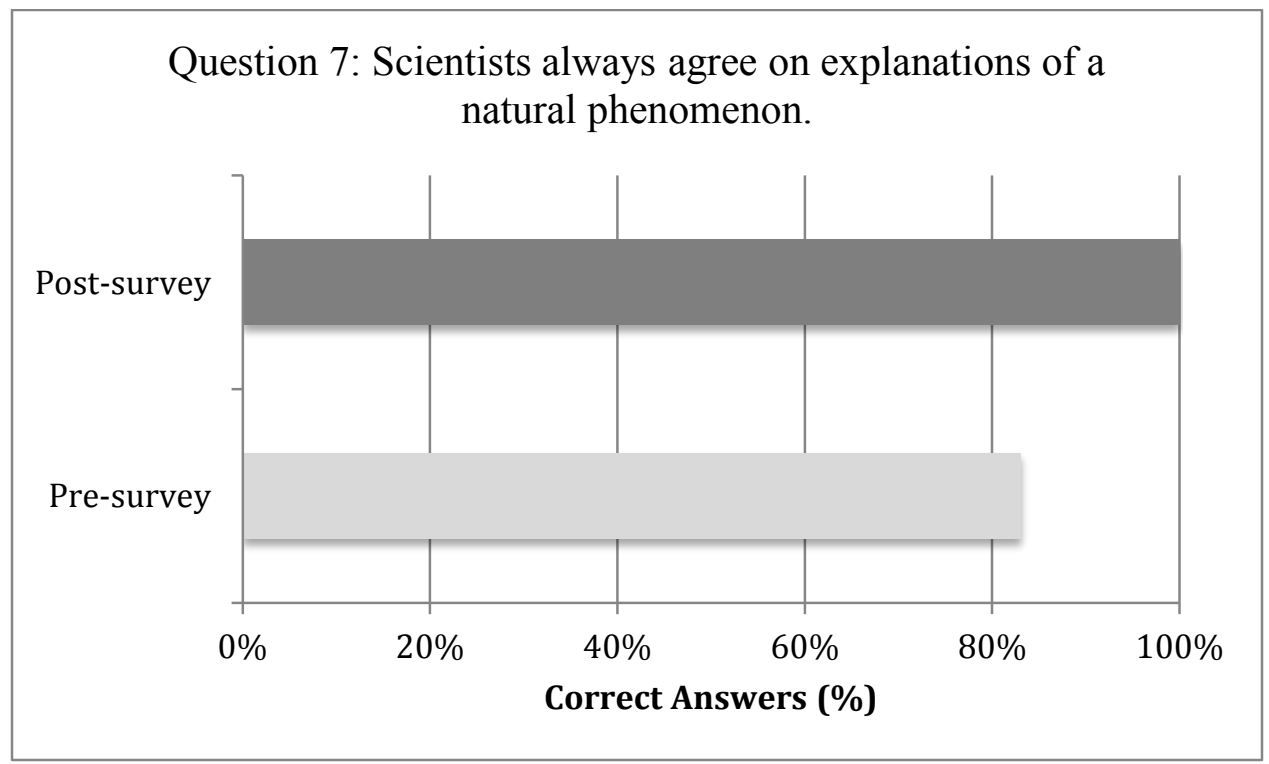

Figure 4. Average scores on the seventh question of the pre- and post-survey. $n=6$

Participants' ability to demonstrate their understanding of this core theme did not change statistically during the project (Tables 3 and 4). Initially, volunteers demonstrated a clear understanding of this aspect on the online pre-survey with high score average of $80 \%$, and continued to experience a slight increase during the pre-test (Fig. $3 \& 4$ ). Only two participants incorrectly answered the first post-interview question pertaining to this 
aspect. Interviewees were asked to describe the likelihood of collecting the same data during the next monitoring season. Next, they had to describe the type of influence their answer would have on scientific knowledge. All but two participants made the accurate claim that they would not be able to collect the same data two years in a row due to:

- Environmental changes

- Natural variability in owl behavior and population sizes

Participants used the above themes as examples that help address how scientific knowledge evolves. Overall, participants were aware of the possibility and implication of changing data to the field of scientific knowledge.

Aspect 3 The next core theme of NOS, describes the need for a scientifically literate person to understand that the field of science is built by a process that is unique from other types of knowledge.

Aspect 3: Science is a way of knowing.

The Next Generation Science Standards describe the particular characteristics that separate Science from other types of knowledge as, "use of empirical standards, logical argument, and skeptical review“(NRC, 2012, Nature of Science pg. 6). Through remodeling the owl monitoring program together, participants got hands-on experience with the scientific process and the theories that support it. While editing and refurbishing the monitoring project, the participants were encouraged to discuss ways to meet both their needs and values within the field of science. For example, in the past years of the project participants would play recorded owl calls to attract the birds. This process often allowed participants to call in a greater variety of owl types than if they were just 
listening, so they wanted to keep the technique in the protocol. On the other hand, the type of questions this project was aiming to answer about owl presence and behavior could only be answered by a protocol that involved passive listening intervals.

Participants discussed the need to adopt the passive protocol, while also acknowledging that they would likely hear fewer species.

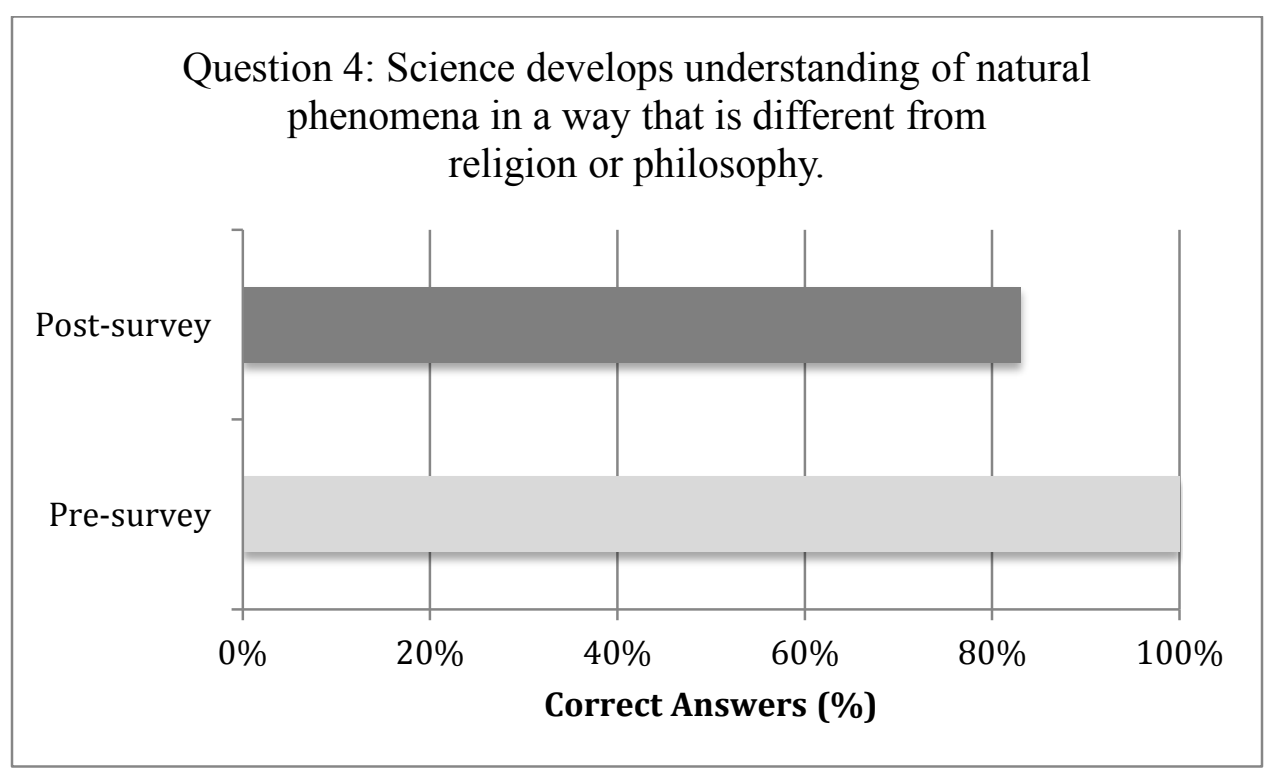

Figure 5. Average scores on the fourth question of the pre- and post-survey. $n=6$

The owl monitors' ability to demonstrate their understanding of this core theme did not statistically change after the treatments (Table 4, Appendix C, Fig. 5 and Fig. 7). 


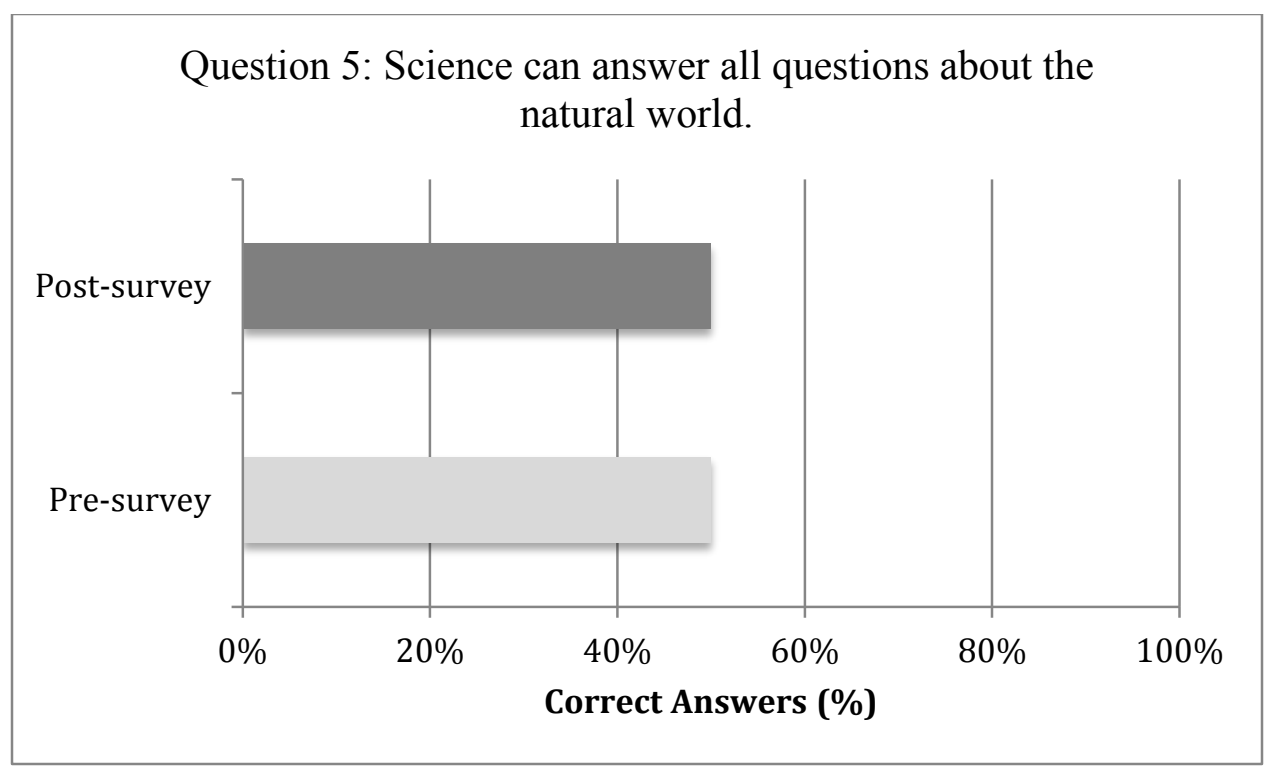

Figure 6. Average scores on the fifth question of the pre- and post-survey. $n=6$

As an attempt to clarify the depth of volunteers' understanding the researcher asked interviewees if they believed that given enough resources and time, the field of science could answer all the scientific questions about owls. Only one participant believed that this was a possible scenario. Participants that answered with question correctly gave multiple reasons

- There are too many assumptions involved to answer all questions.

- Animals and climate are changing in ways that we cannot see

These answers show that participants are able to understand the limitations of scientific research. They seemed to understand that the researcher can only control for random chance, but that they cannot control the natural world. They also understood the danger in assuming that natural a phenomenon never changes over time. One participant stated:

"I think the more resources the more likely it is to more fully understand a species, but I personally believe there is more than meets the eye. So when we start thinking 
we know everything about a species is when it becomes dangerous. "

One participant, who displayed an accurate demonstration of understanding, compared this question to the study of the human brain:

"You know, we don't really understand the human brain yet, right? And there have been a lot of resources going towards that and a lot that they thought about it in the past was wrong. But I do think the more resources the better chances we have at understanding a species."

Overall, from the survey answers volunteers seemed to have a basic understanding of this aspect of NOS before they participated in the project and the interview.

Aspect 4 Science is a field imagined, defined, designed and implemented by humans. The field is built through human experience and observations of phenomena within the natural world. To be scientifically literate, one must be able to critically reflect on scientific knowledge and to continue to be aware of the type of human influences that define said knowledge.

Aspect 4: Science is a human endeavor

This discussion took place when participants were provided local newspaper articles written about contentious barred owl monitoring techniques being implemented by the United State government. The researcher sent out the original articles, public responses to the topic and resources for the participants to learn more on the subject if they so choose.

When owl monitors were given time to reflect on and contribute to the remodeling 
of the original project, they were also practicing this aspect of NOS.

Volunteers' ability to host a discussion about the difference between the influences of personal values on the process of building scientific knowledge, demonstrates that they did understand some ways that humans influence the field as a whole. With ease, the monitors were able to talk about possible emotional and empirical viewpoints, while also identifying how those viewpoints would change the scientific knowledge behind the subject.

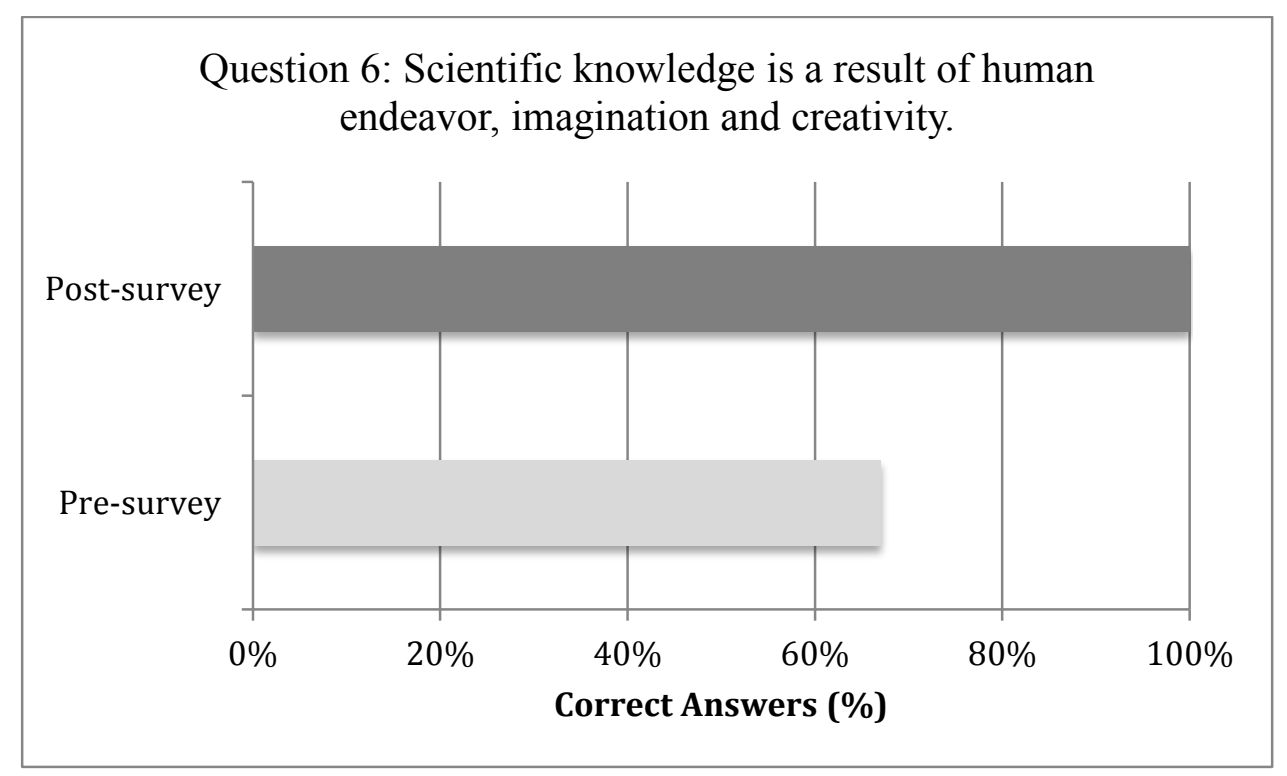

Figure 7. Average scores on the sixth question of the pre- and post-survey. $n=6$

Participants' ability to demonstrate their knowledge of this NOS aspect on the questionnaire increased after they experienced the treatment, although this change was not statistically significant (Table 4 and Fig. 6). 


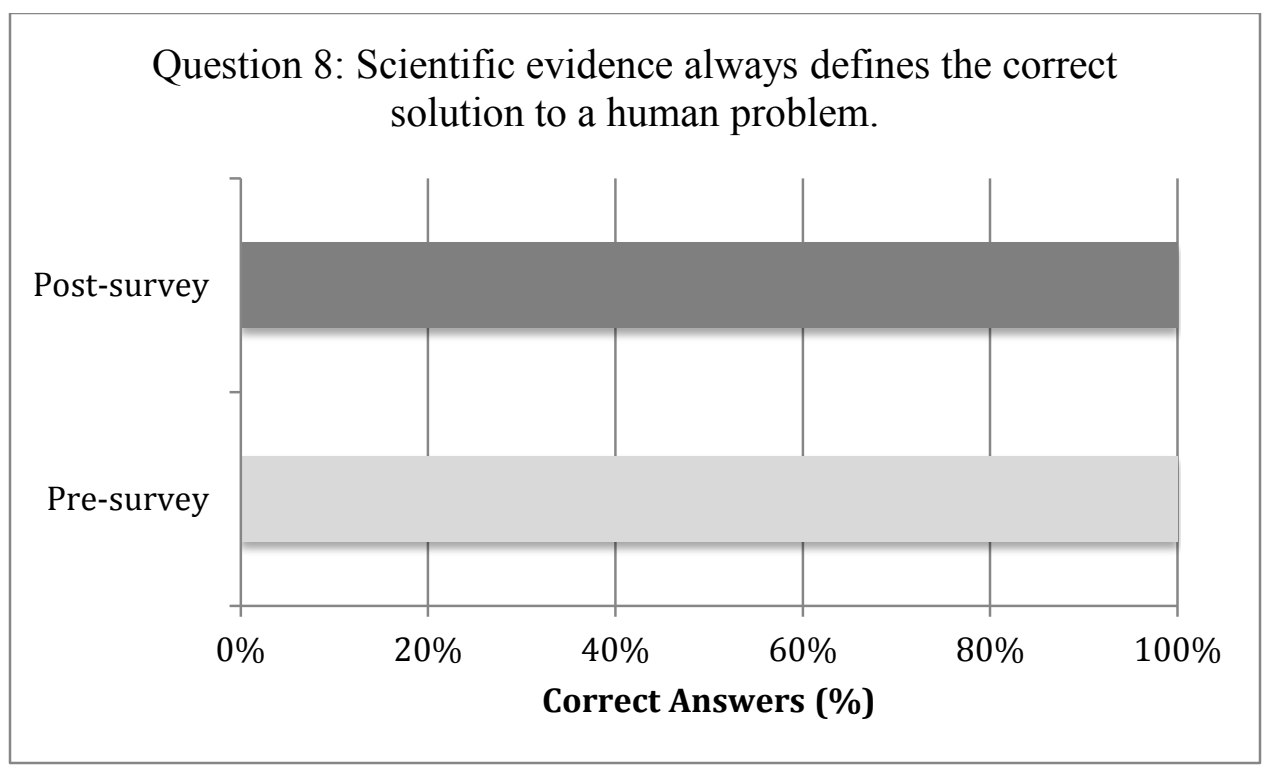

Figure 8. Average scores on the eighth question of the pre- and post-survey. $n=6$

Answers to question 8 were correct before and after the treatment suggesting that volunteers had a basic understanding of this aspect of NOS before they participated in the project (Appendix C and Fig. 8).

Volunteers' response to the post-interview confirmed that understanding as well. Not only were they able to accurately describe ways that society influences scientific data collection and use, but they were also able to describe whether or not a scientist could be truly objective during the post-interview. All but one participant demonstrated their understanding of this concept. Common themes that were exposed from coding answers to this interview question were:

- Objectivity will depend on the individual's background knowledge and experience in the subject.

- Too many variables control a situation to be objective

Volunteers' ability to answer this question correctly demonstrates that they realize the 
field of science is continually challenged to align the scientific opinions of researchers from different backgrounds and knowledge bases. As one volunteer said,

"Objectivity is based on what you believe it to be."

The only participant that believed scientists could be completely objective produced answers with these themes:

- Yes, if they avoid assumptions as best as possible.

- Yes, if they are conservative with the data they collect and use.

These themes showed that the volunteers had an incorrect or naïve understanding of the limits that exist within scientific research.

During the interview process, respondents were asked to describe ways the public can influence the use and collection of a scientist's data. The intention of this question was to expose the owl monitors' ability to recognize the existence and implications of emotional and empirical viewpoints the society provides on the field of science. In retrospect, this question may have been more informative to the teacher if the participants were asked to explain the difference between society's influence on science vs religion or philosophy. The coding of these answers produced seven themes that help frame the respondents' understanding of this aspect of NOS.

Each theme described a different way that society can be involved in the scientific process.

- Citizen science - data collection and results depends on how well the volunteer scientists are trained and their background.

- Financial - societal support for a project may enable it to receive more 
money, or society may be the source of that money.

- Interest levels - if society is interested in the subject they may provide more support.

- Interpretation of data - results may be interpreted differently by people depending on their values and knowledge pertaining to the subject.

Participants of this case study demonstrated that they had an intermediate understanding of the 4 core themes of NOS in question. They were unable to experience a significant change in their ability to show they have deep comprehension of the aspect, yet some participants did show a slight increase in that ability after the treatment was completed. Participants exhibited a slight increase in their capacity to verbalize their understanding of the type of evidence that is required to create scientific knowledge, Aspect 2.

Participants also demonstrated an increase in their ability to explain science as a human endeavor, Aspect 4. The other potential area of knowledge gain was exposed when participants answered survey and interview questions for the core theme of science as a human venture designed by our experience in the natural world.

\section{Embedded Researcher}

Benefits Small-scale citizen science projects allow for a more intimate relationship between the lead researcher and the volunteer scientists. Larger projects involve training, conversations and other interactions between volunteers and lead scientist to occur only online, or at only initial mass training event (Bonney et al., 2009a). The following case study applied a different model of researcher and volunteer interactions that allowed both 
parties to participate in the entire research process.

Participants were given two opportunities (an online survey and an interview) to offer insight about the presence of an embedded researcher, a technique new to the season that occurred during the research. Their results were across the board, starting at, "dramatically" and ending at, "not at all." The researcher was able to expose common themes on how the presence of a practiced researcher changed the participants' experience with the project (Table 4).

Pertaining to the scientific aspect of the project, participants reported that the presence of an embedded researcher increased their sense of legitimacy in the project.

Some common themes were:

1. Reassuring, because the researcher knew the scientific process

2. Provided authenticity

3. Added value

4. Provided accountability for the data collection and analysis

5. Increased productivity and focus

6. Provided structure and organization

7. More information and resources were made available than in years past

According to the first theme, the presence of someone that is experienced with the scientific protocol may have given participants more confidence in their ability to be volunteer scientists.

The second, third and fourth theme indicated that participants were feeling confident in the legitimacy of the project and its purpose because of the presence of the embedded researcher. Past research on authentic learning experiences have found that learners become more self-regulating and more aware of their own thinking and behaviors with the learning educational setting (Hung, Cheah Horn Mun, Cheung, 2004). 
This may be why some participants claim that the presence of an imbedded researcher increased productivity. In the survey, one participant wrote about how the lead researcher kept them focused and able to check themselves on their ability to perform research,

"It helped to remember that the purpose of the project is not to allow me time in the dark with fascinating critters, but rather to gather information on the presence, location, frequency, habits, etc. of several varieties of owls and to organize that information into a useful format."

The fifth theme shows that the embedded researcher makes the participants feel that the project is structured and organized. This is reflective of the background and experience of a researcher in this type of study. The nature of action research requires a process for working through each problem with the volunteers and in this instance required the researcher for this study to have proficient organizational skills.

Participants also reported an educational advantage to having an embedded researcher within the project. The researcher was able to provide learning material that evolved with the learning progression. Also, the embedded researcher was continuously available to help locate and disperse resources requested by participants throughout the project. This may have led to volunteers having a deeper understanding of the research aspect. One participant stated:

"Having more information made the experience more enjoyable and productive for me than last year."

According to experts, successful citizen science experiments require multiple types of educational resources (Bonney et al., 2009a). Due to the action research model of learning together, the embedded researcher in this study was able to provide multiple types of literature and media that matched her participants' learning needs. Some owl 
monitors preferred learning in an online setting, while others wanted books and printed materials. During the treatment the researcher frequently asked her volunteers about their learning needs to promote sustained engagement in the project. If the researcher followed the more common citizen science model of only talking with participants when they emailed with inquiries, her ability to address the volunteers' learning needs may have insufficient.

Participants who were new to the project reported having a positive experience with the embedded researcher. During one interview the participant was quoted saying,

"Well, I don't have anything to compare it to, because although I have done a lot of volunteer work, this is the first one that has a scientific component or especially when there were questions back and forth. Could it be this, could it be that. Uh, that things would get dropped if you haven't been there or just made it up. Ok, well lets just say why don't we all agree that it's this. So it's kinda a refinement of the accuracy, a chance to sit with the information until you and we felt like we had an accurate presentation, you were right there. If we had to wait until the end of the project or until we got feedback I think a lot of information would be dropped. And I think we, as volunteers, would not have learned as much as we do or as we have without a scientist to help us get it, but also the project would I think, suffer. I think it wouldn't have nearly the depth and the breadth that it does without a knowledgeable person right there. "

Limitations Two participants reported that the embedded researcher had no effect on their experience with the project. The themes of those answers were:

- Already an experienced researcher

- Missed the training and educational event

Some volunteers that joined the owl monitoring project came from professional backgrounds in scientific research, specifically ornithology. Those participants may have not needed the help offered by the embedded researcher. 
The second theme alludes to another limitation to the presence of an embedded researcher. Which is that while they are more available than project leaders in most citizen science studies, they can only help volunteers that put forth the effort to participate in each activity. Many researchers have shown that volunteers join these types of projects for various reasons; some may not want to learn extra knowledge, while others may give more effort in order to engage in learning activities (Raddick et. al 2010).

\section{Conclusion}

Over the last few years, the importance of citizen science projects has become obvious (Delaney et al. 2007, Hurlbert and Liang 2012, and Worthington et al. 2012). The future of science literacy is enhanced through hands-on experience with actual science, and the collaboration between scientists and the public (Bonney et al. 2009b). Scientists and educators have been diligently working to find a model that allows volunteers and researchers to benefit while also creating a more science literate society (Bonney et al. 2009b, Delaney et, al, 2007, Hurlbert \& Liang, 2012). This case study addressed how to support the development of an understanding of the nature of science in the context of the Next Generation Science Standards within a citizen science project. The researcher's approach was centered on four core themes of the Nature of Science and the intersection of those understandings within different aspects of the treatment, an owl monitoring project. Participants did demonstrate a slight increase in their knowledge of the two of the four proposed aspects of the Nature of Science through participating in the Tryon Creek Owl Monitoring Project. Volunteer owl monitors were able to demonstrate a 
slight increase in their understanding how scientific knowledge evolves as new evidence is exposed, and the idea that science is driven by human curiosity and effort. However, participation in this particular citizen science project did not show a statistically significant increase in their understanding of any aspect. Measuring the change in understanding was a challenge because many monitors entered the project with some prior knowledge of the four aspects, so growth was limited. This is not to say that citizen science projects in general cannot support a gain in NOS understanding. Research outcomes from this study have exposed some of the difficult aspects of analyzing the educational effects of participating in a citizen science project. This paper can contribute to the body of literature that allows organizers of citizen science projects to continually reflect on learning experiences and material of the past with the intention of creating an effective model for teaching NOS within a project.

The second goal of this study was to identify the benefits and limitations of approaching the project as an embedded researcher. As the embedded researcher, the imbedded reasearcher led participants through an owl monitoring project that involved principles from active research, that were measured by interview sessions and online surveys. Active research proved to be an effective guide to help citizen science practitioners meet their personal needs while supporting the needs of science. This model enabled a science professional and citizen scientists to work alongside each other to reenergize the past owl monitoring project. The importance of an imbedded researcher within a citizen science project was found to be positive. During post-treatment interviews, participants reported the presence of the embedded researcher as a positive 
addition to the project. Although the position is time consuming, the researcher was reported to have provided scientific integrity, and motivation to many participants.

\section{Recommendations}

The following section will outline recommendations from the researcher and volunteers gathered during the pre-interview. These recommendations apply to the Tryon Creek project, but may also benefit leaders of similar citizen science projects. During this project, the researcher was limited on the amount of time she could provide towards the project. Without financial backing, this citizen science project depended on volunteer time of both the lead researcher and the volunteers. Multiple participants suggested offering more tasks to volunteers with a background in the science or owl research. In the future of this project, or others like it, the project manager may benefit from offering a participation tier that allows volunteers to give more time and effort if they are willing. This may require offering small training sessions for each task, but this technique would allow the project manager to pass some aspects of the projects off to participants, which also has the benefit of allowing the manager more time to attend to other areas of the project.

Similar to how Hurbert and Liang (2012) used a quiz to test accuracy of the participants, project leaders of the owl monitoring project may gain more accurate data through testing their volunteers. At the beginning of each monitoring session, the leader could play a series of calls and ask participants to identify the birds calling and write their answers on a sheet of paper with their name and date. The leader could then review the 
answers with participants and ask to collect the quizzes. Not only would this be a good way for participants to practice the calls, a suggestion made in a post-interview, but the leader could also continually assess their volunteer scientists' accuracy at identifying owls.

Over the years professionals have created a list of tips to help citizen science project leaders increase the scientific knowledge of their participants (Bonney et al. 2009b, Riddick et al. 2010). During this case study the researcher was using a passive method to teach participants about the aspect of NOS. This meant that she did not provide participants with literature on Nature of Science, nor did she teach about each aspect in great detail. The treatment she used was discussing the NOS aspects in light of the owl monitoring project, and through exploring the scientific process and practices while building and implementing the project. Participants demonstrated a slight gain in understanding of the multiple NOS aspects explored during the treatment. According to Jordan, Ballard, and Philips (2012) further study of how to better teach these aspects should incorporate more learning material that is more explicit to the learning goals. These materials may involve posters that list the NOS core themes, handouts and resources that allow the participant to pursue the subject on their own, or to include a section on the NOS aspects within the training lectures and discussion. When each aspect is presented, the learner may benefit from having the NOS aspect presented by itself and then used within the context of owl monitoring or ecology. Other citizen science researchers have tested all learning materials to ensure they align with learning activities 
(Jordan, Ballard, and Philips, 2012).

Almost all post-interviewees noted their appreciation for the discussions that took place after each monitoring event. These events allowed participants to manipulate and study the data they collected, which has been claimed as one of the most educational features of citizen science (Bonney et al., 2009a).

Within the design model for successful citizen science projects, the Cornell Lab of Ornithology notes the need for an interdisciplinary support team (Bonney et al. 2009b). This breadth of support may be difficult for a small-scale study such as the one that took place within this case study. Technical support enables larger citizen science projects to offer extensive websites to their volunteers. These sites can offer participants access to resources, educational material and an opportunity for manipulation of the data they collected within the project (Bonney et al. 2009). Originally the researcher of this study proposed such a website as a tool for learning and a tool for collecting data on participants' understanding of the core themes of NOS. The website was proposed to offer a way for the volunteers to enter the data they collect for Tryon Creek and a link for them to add their data to an international bird monitoring database called eBird. Through use of a centralized website, volunteers would get the opportunity to learn data entry, how the data can contribute to larger projects (eBird). The site would have offered purpose and techniques of other owl monitoring projects. The site would also provide contact information of Tryon staff, a PDF of the training packet, and links to other owl monitoring projects. Expert designers of citizen science projects have reported that an interdisciplinary support group is important for any successful citizen science project 
(Bonney et al., 2009b). In the future, online projects, such as the website, may get completed if there are multiple sources of technological support.

A way to offer extra training to participants, but not take up more of the park staffs' time and facility, would be to video tape the common mini-lectures that would be offered before a monitoring session. Those videos should then be distributed to participants when needed via Email or made accessible on the website. For example, by taping the mini-lecture on owl calls and emailing it to participants, they may be able to catch-up to participants that cannot attend lectures. More access to training may help increase the accuracy of the data collected because volunteers would have more time to practice the protocol. These videos would be cost-effective, because they would need little production effort and could be made only once.

Citizen Science projects that take place in the same area as a University may benefit from proposing teamwork between biology students and project staff. The project could be presented as a resume building activity for students, a setting where they learn about working with the public, organizing a scientific study, and applying the scientific process. The project could come with incentives for the students to invest their time and effort by providing research or practicum credit. Coordination of multiple local organizations can lead to community level impacts and/or even an increase in social capital within the community (Jordan, Ballard and Philips 2012).

Multiple participants suggested that the researcher provide a training review day a few weeks into the project. From a teaching aspect, this second training opportunity could potentially help the volunteers reflect on the scientific process since they would 
have applied it already and it could act as an occasion to find and clarify assumptions that may be at play when collecting data. 


\section{Works Cited}

Abd-El-Khalick, F., Bell, R.L., \& Lederman, N.G. (1998). The nature of science and instructional practice: Making the unnatural natural. Science Education, 82, 417437.

Bradbury Huang, H. (2010). What is good action research?: Why the resurgent interest? Action Research, 8(1), 93-109. DOI: 10.1177/1476750310362435.

A. Bonney, R., Cooper, C. B., Dickinson, J., Kelling, S., Phillips, T., Rosenberg, K. V., and Shirk, J. (2009). Citizen Science: A developing tool for expanding science knowledge and scientific literacy. BioScience. 59(11), 977-984.

B. Bonney, R., Ballard, H., Jordan, R., McCallie, E., Phillips, T., Shirk, J., \& Wilderman, C. C. (2009). Public Participation in Scientific Research: Defining the Field and Assessing Its Potential for Informal Science Education. A CAISE Inquiry Group Report. Online Submission.

Brossard, D., Lewenstein, B., Bonney, R. (2005). Scientific knowledge and attitude change: The impact of a citizen science project. International Journal of Science Education, 27(9), 1099-1121.

Crall, A. W., Jordan, R., Holfelder, K., Newman, G. J., Graham, J., Waller, D. M., (2013). "The impacts of an invasive species citizen science training program on participant attitudes, behavior, and science literacy". Public Understanding of Science. 22(6), 745.

Delaney, D. G., Sperling, C. D., Adams, C.S., Leung, B. (2008). Marine invasive species: validation of citizen science and implications for national monitoring networks. Biological Invasions, 10, 117-128.

Elegant Word Press. (2011). Friends of Tryon Creek. http://www.tryonfriends.org

Fry, H., Ketteridge, S., \& Marshall, S. (2008). A handbook for teaching and learning in higher education: Enhancing academic practice. Routledge.

Hamer, T. E., Forsman, E. D., Fuchs, A. D. Walters, M. L. (1994) Hybridization between Barred and Spotted Owls. The Auk, 111(2), 487-492.

Hung, D., Tan, S. C., \& Koh, T. S. (2006). Engaged learning: Making learning an authentic experience. In Engaged learning with emerging technologies (pp. 29-48). Springer Netherlands. 
Jordan, R. C., Ballard, H. L., Philips, T. B. (2012). Key issues and new approaches for evaluating citizen-science learning outcomes. Frontiers in Ecology and the Environment. 10, 307-309.

Kelly, E. G., Forsman, E. D. and Anthony, R. G. (2003) Are Barred Owls displacing Spotted Owls? The Condor, 105, 45-53.

Lederman, N. G., Abd-El-Khalick, F., Bell, R. L., and Schwartz, R. S. (2002) Views of Nature of Science questionnaire: Toward valid and meaningful assessment of learners' conceptions of Nature of Science. Journal of Research in Science Teaching, 39(6), 497-521.

Levesque, P. G., (2002). 2002 Final Report. Nocturnal owl Monitoring at Rocky Point Bird Observatory. 2002 Final Report.

Liang, Z., Hurlbert, A. H. (2012). Spatiotemporal Variation in Avian Migration Phenology: Citizen Science Reveals Effects of Climate Change. PLoS ONE, 7(2), e31662.

National Research Council (2012). A Framework for K-12 Science Education: Practices, Crosscutting Concepts, and Core Ideas. Washington, DC: The National Academy Press.

NGSS Lead States. 2013. Next Generation Science Standards: For States, By States. Washington, DC: The National Academies Press.

Raddick, J. M., Bracey, G., Gay, P. L, Lintott, C.J., Murray, P., Schawinski, K., Szalay, A. S., Vandenberg, J. (2010). Galaxy Zoo: Exploring the motivations of citizen science volunteers. Astronomy Education Review, 9, 010103.

Schwartz, R. S., Lederman, N. G., Crawford, B. A. (2004). Developing views of nature of science in an authentic context: An explicit approach to bridging the gap between nature of science and science inquiry. Science Education 88(4), 610-645.

Trumbull, D. J., Bonney, R., Grudens-Schuck, N. (2005) Developing material to promote inquiry: Lesson learned. Science Education, 89: 879-900.

Trumbull D. J., Bonney R., Bascom K, and Cabrel A. (2000). Thinking scientifically during participation in a citizen-science project.

Science Education-Netherlands 84, 265-75.

Worthington, J. P., Silvertown, J., Cook, L., Cameron,. Dodd, M., Greenwood, R. M., McConway, K., Skelton, P. (2012). Evolution MegaLab: a case study in citizen science methods. Methods in Ecology and Evolution, 3, 303-309. 
Vermeylen, F. (2005) Censoring data. StatsNews, 67. Retrieved from https://www.cscu.cornell.edu/news/statnews/stnews67.pdf 


\section{Appendix A: Survey and Interview Questions}

\section{Online Survey}

The online questionnaires asked the following questions:

Directions - Please circle one number to indicate your agreement with the following statement:

1. There is just one right answer from a scientific investigation.

2. Scientist use empirical evidence to develop theories explaining natural phenomena.

3. Scientific theories can change based on new evidence.

4. Science develops understanding of natural phenomena in way that is different from religion or philosophy.

5. Science can answer all questions about the natural world.

6. Science knowledge is a result of human endeavor, imagination and creativity.

7. Scientists always agree on explanations of a natural phenomenon.

8. Scientific evidence always defines the right solution to a human problem.

Question 9 was only included in the post-survey.

9. In what way did the presence of a practiced researcher affect your experience with the owl monitoring project? 


\section{Interview 1}

Owl monitoring volunteers were asked the following questions:

1. What was your experience with the project like in the past?

2. What aspects of the project did you like? What did you dislike about the project?

3. How do you think the program can be improved?

4. How were you prepared to collect data?

5. Do you know how the program coordinator used the information? Can you suggest any other ways to use the data?

6. What kind of knowledge did you gain through participating in this project?

7. What do you think the purpose of this study is?

8. Why is that purpose important?

9. Do you feel you were doing science during this project? If yes, can you tell me more about that? If no, can you explain why not?

10. Do you think this project is based on any scientific theories? Please explain. 


\section{Interview 2}

1. What was your motivation for joining this project?

2. Were you satisfied by the project as far as meeting your motivation?

3. Do you think the data we collected could be used to further scientific knowledge? Why?

4. If we ran this program again next year do you think we will get the same data? If no, what would that mean for scientific knowledge?

5. How do you think society can influence the use and collection of a scientist's data?

6. Can scientist be completely objective within their research? Please explain.

7. If we were given enough resources and time could we answer all the scientific questions about owls?

8. How did the embedded researcher change your experience if at all?

9. What do you think the project needs to get better?

10. What suggestions do you have pertaining to the protocol and methods used?

11. What did you like the most about the project this year? 


\section{Appendix B: Coding Instruments}

\section{Coding rubric for NOS survey answers}

Nature of Science Aspects as presented by the Next Generation Science Standards.

\begin{tabular}{|c|c|c|}
\hline & Understandings about the Nature of Science & \\
\hline Aspect & Correct answers or concepts & \\
\hline $\begin{array}{l}\text { Scientific } \\
\text { knowledge } \\
\text { is based on } \\
\text { empirical } \\
\text { evidence }\end{array}$ & $\begin{array}{l}\text { - Science knowledge is based on empirical evidence. } \\
\text { - Science disciplines share common rules of evidence used to evaluate } \\
\text { explanations about natural systems. } \\
\text { - Science includes the process of coordinating patterns of evidence } \\
\text { with current theory. } \\
\text { - Science arguments are strengthened by multiple lines of evidence } \\
\text { supporting a single explanation. }\end{array}$ & 1,2 \\
\hline $\begin{array}{l}\text { Scientific } \\
\text { knowledge } \\
\text { is open to } \\
\text { revision in } \\
\text { light of } \\
\text { new } \\
\text { evidence }\end{array}$ & $\begin{array}{l}\text { - Scientific explanations can be probabilistic. } \\
\text { - Most scientific knowledge is quite durable but is, in principle, } \\
\text { subject to change based on new evidence and/or reinterpretation of } \\
\text { existing evidence. } \\
\text { - Scientific argumentation is a mode of logical discourse used to } \\
\text { clarify the strength of relationships between ideas and evidence that } \\
\text { may result in revision of an explanation. }\end{array}$ & 3,7 \\
\hline $\begin{array}{l}\text { Science is a } \\
\text { way of } \\
\text { knowing }\end{array}$ & $\begin{array}{l}\text { - Science is both a body of knowledge that represents a current } \\
\text { understanding of natural systems and the processes used to refine, } \\
\text { elaborate, revise, and extend this knowledge. } \\
\text { - Science is a unique way of knowing and there are other ways of } \\
\text { knowing. } \\
\text { - Science distinguishes itself from other ways of knowing through use } \\
\text { of empirical standards, logical arguments, and skeptical review. } \\
\text { - Science knowledge has a history that includes the refinement of, and } \\
\text { changes to, theories, ideas, and beliefs over time. }\end{array}$ & 4 \\
\hline $\begin{array}{l}\text { Science is a } \\
\text { human } \\
\text { endeavor }\end{array}$ & $\begin{array}{l}\text { - Scientific knowledge is a result of human endeavor, imagination, } \\
\text { and creativity. } \\
\text { - Individuals and teams from many nations and cultures have } \\
\text { contributed to science and to advances in engineering. } \\
\text { - Scientists' backgrounds, theoretical commitments, and fields of } \\
\text { endeavor influence the nature of their findings. } \\
\text { - Technological advances have influenced the progress of science and } \\
\text { science has influenced advances in technology. } \\
\text { - Science and engineering are influenced by society and society is } \\
\text { influenced by science and engineering. }\end{array}$ & 6 \\
\hline
\end{tabular}




\section{Appendix C. Table}

Coding results of Interview. $\mathrm{n}=5$

\begin{tabular}{|c|c|c|c|c|c|c|}
\hline Question & Responses & & & & & \\
\hline $\begin{array}{l}\text { What was } \\
\text { your } \\
\text { experience } \\
\text { like? }\end{array}$ & Positive & Neutral & & & & \\
\hline $\begin{array}{l}\text { What } \\
\text { aspect of } \\
\text { the project } \\
\text { did you } \\
\text { enjoy? }\end{array}$ & $\begin{array}{l}\text { Hearing } \\
\text { and } \\
\text { Learning } \\
\text { about owls } \\
\text { in the park }\end{array}$ & $\begin{array}{l}\text { *Learning } \\
\text { about owls } \\
\text { in the park } \\
\text { and the } \\
\text { scientific } \\
\text { framework }\end{array}$ & $\begin{array}{l}\text { Location of } \\
\text { the project }\end{array}$ & $\begin{array}{l}\text { The } \\
\text { information } \\
\text { and training } \\
\text { provided }\end{array}$ & & \\
\hline $\begin{array}{l}\text { What } \\
\text { aspect of } \\
\text { the project } \\
\text { did you } \\
\text { dislike? }\end{array}$ & *Methods & $\begin{array}{l}\text { *Trouble } \\
\text { with } \\
\text { equipment }\end{array}$ & $\begin{array}{l}* \text { Navigation } \\
\text { at night }\end{array}$ & $\begin{array}{l}\text { Not } \\
\text { prepared } \\
\text { well enough } \\
\text { to feel } \\
\text { confident in } \\
\text { orienteering } \\
\text { ability }\end{array}$ & & \\
\hline $\begin{array}{l}\text { How do } \\
\text { you think } \\
\text { the } \\
\text { program } \\
\text { can be } \\
\text { improved? }\end{array}$ & $\begin{array}{l}\text { Standardize } \\
\mathrm{d} \text { data } \\
\text { collection }\end{array}$ & $\begin{array}{l}\text { Simple } \\
\text { methods }\end{array}$ & $\begin{array}{l}\text { Clarification } \\
\text { of } \\
\text { expectations } \\
\text { and } \\
\text { instructions }\end{array}$ & $\begin{array}{l}\text { Opportunity } \\
\text { for } \\
\text { discussion } \\
\text { of data }\end{array}$ & $\begin{array}{l}\text { Provide } \\
\text { more } \\
\text { information } \\
\text { about the } \\
\text { owls }\end{array}$ & $\begin{array}{l}\text { Larger } \\
\text { learnin } \\
\mathrm{g} \\
\text { compo } \\
\text { nent: } \\
\text { scientif } \\
\text { ic } \\
\text { proces } \\
\mathrm{s}, \\
\text { applica } \\
\text { tion of } \\
\text { data }\end{array}$ \\
\hline $\begin{array}{l}\text { How were } \\
\text { you } \\
\text { prepared to } \\
\text { collect } \\
\text { data? }\end{array}$ & $\begin{array}{l}\text { Brief } \\
\text { training }\end{array}$ & $\begin{array}{l}\text { Provided } \\
\text { datasheets to } \\
\text { fill out }\end{array}$ & $\begin{array}{l}\text { Learned } \\
\text { from } \\
\text { returning } \\
\text { participants }\end{array}$ & & & \\
\hline
\end{tabular}




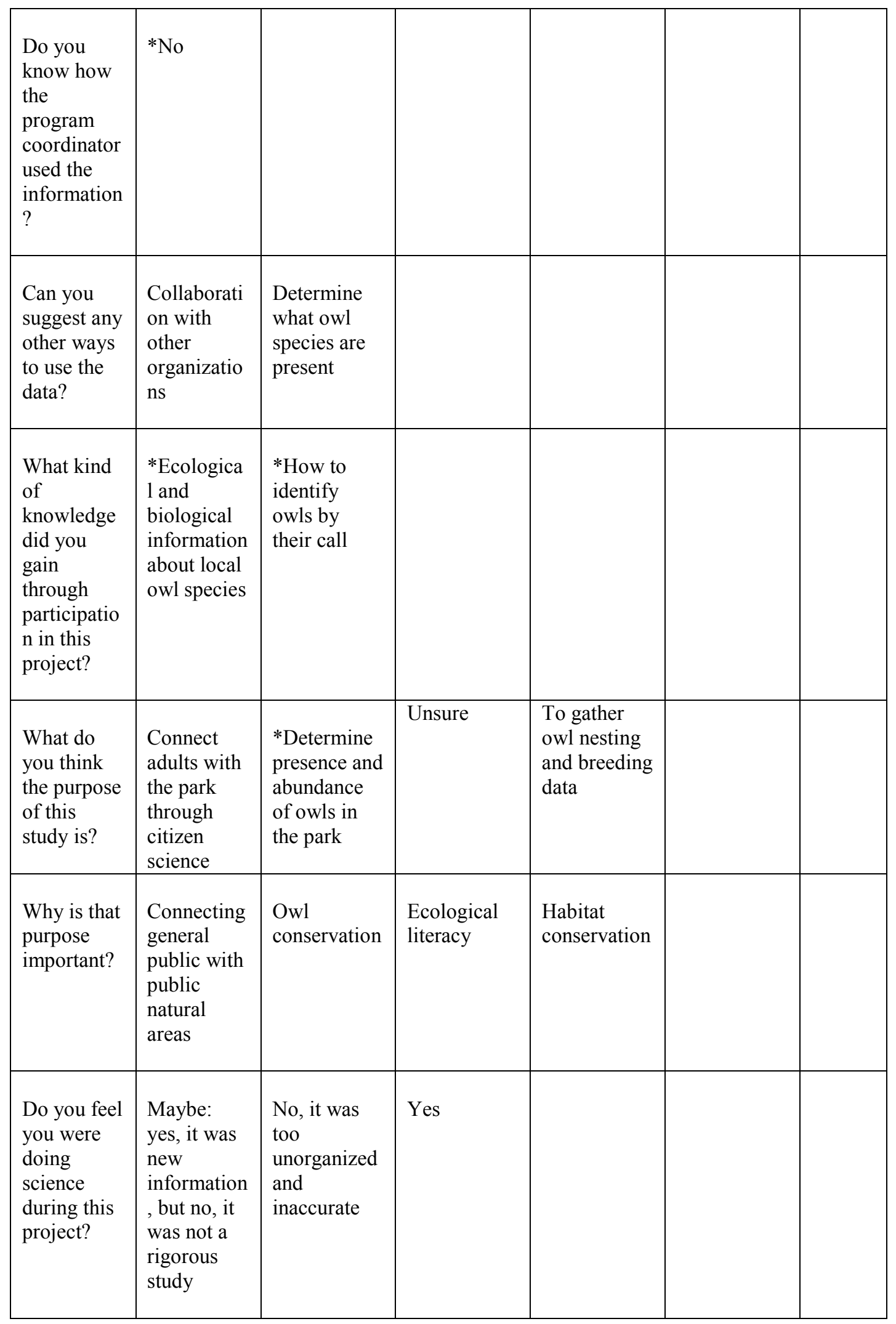




\begin{tabular}{|l|l|l|l|l|l|l|}
\hline $\begin{array}{l}\text { Do you } \\
\text { think this } \\
\text { project is } \\
\text { based on } \\
\text { scientific } \\
\text { theories? }\end{array}$ & $*$ Yes & $\begin{array}{l}\text { *Unable to } \\
\text { explain what } \\
\text { theory }\end{array}$ & Unsure & $\begin{array}{l}\text { Theories of } \\
\text { conservation } \\
\text { and } \\
\text { observation }\end{array}$ & & \\
& & & & & \\
\hline
\end{tabular}

* indicates more than one participant provided this answer 
Coding results from the post-interview. $\mathrm{n}=9$

\begin{tabular}{|c|c|c|}
\hline Interview Question & Answer Themes & Total \\
\hline $\begin{array}{l}\text { What was your motivation } \\
\text { for joining the project? }\end{array}$ & $\begin{array}{l}\text { - To learn about and hear owls } \\
\text { - Contribute to conservation } \\
\text { - Meet people with similar interests } \\
\text { - Location and hiking }\end{array}$ & $\begin{array}{l}4 \\
2 \\
2 \\
2\end{array}$ \\
\hline $\begin{array}{l}\text { Were you satisfied by the } \\
\text { project as far as meeting } \\
\text { your motivation? }\end{array}$ & -Yes & 9 \\
\hline $\begin{array}{l}\text { What do you think the } \\
\text { project needs to get better? }\end{array}$ & $\begin{array}{l}\text { - Additional training events (whole-day and throughout } \\
\text { season) } \\
\text { - Team up with college students to get more } \\
\text { professional help } \\
\text { - Offer more responsibility to volunteers }\end{array}$ & \\
\hline $\begin{array}{l}\text { What suggestions do you } \\
\text { have pertaining to the } \\
\text { protocol and methods used? }\end{array}$ & $\begin{array}{l}\text { - All time intervals should be } 8 \text { minutes long } \\
\text { - Separate "stop" and "start" on datasheet } \\
\text { - Stand farther apart facing different directions when } \\
\text { listening }\end{array}$ & $\begin{array}{l}8 \\
6 \\
1\end{array}$ \\
\hline $\begin{array}{l}\text { What did you like the more } \\
\text { about the project this year? }\end{array}$ & $\begin{array}{l}\text { - Walking in the park at night } \\
\text { - Meeting other people with similar interests } \\
\text { - Hearing owls } \\
\text { - Hearing owls in an urban setting }\end{array}$ & $\begin{array}{l}4 \\
3 \\
3 \\
2\end{array}$ \\
\hline
\end{tabular}

